\title{
Brown Adipose Tissue Energy Metabolism in Humans
}

\section{OPEN ACCESS}

Edited by:

Mohamed Abu-Farha,

Dasman Diabetes Institute, Kuwait

Reviewed by:

Krzysztof W. Nowak,

Poznan University of Life Sciences, Poland

Michaela Tencerova University of Southern Denmark

Odense, Denmark

*Correspondence:

André C. Carpentier andre.carpentier@usherbrooke.ca

Specialty section:

This article was submitted to

Diabetes,

a section of the journal

Frontiers in Endocrinology

Received: 31 May 2018

Accepted: 20 July 2018

Published: 07 August 2018

Citation:

Carpentier AC, Blondin DP,

Virtanen KA, Richard D, Haman F and

Turcotte ÉE (2018) Brown Adipose

Tissue Energy Metabolism in Humans.

Front. Endocrinol. 9:447.

doi: 10.3389/fendo.2018.00447

\author{
André C. Carpentier ${ }^{1 *}$, Denis P. Blondin ${ }^{2}$, Kirsi A. Virtanen ${ }^{3,4}$, Denis Richard ${ }^{5}$, \\ François Haman ${ }^{6}$ and Éric E. Turcotte ${ }^{7}$
}

${ }^{1}$ Division of Endocrinology, Department of Medicine, Centre de Recherche du CHUS, Université de Sherbrooke, Sherbrooke, QC, Canada, ${ }^{2}$ Faculty of Medicine, University of Ottawa, Ottawa, ON, Canada, ${ }^{3}$ Turku PET Centre, Turku University Hospital, Turku, Finland, ${ }^{4}$ Institute of Public Health and Clinical Nutrition, University of Eastern Finland (UEF), Kuopio, Finland, ${ }^{5}$ Centre de Recherche de l'Institut Universitaire de Cardiologie et de Pneumologie de Québec, Université Laval, Quebec City, QC, Canada, ${ }^{6}$ Faculty of Health Sciences, University of Ottawa, Ottawa, ON, Canada, ${ }^{7}$ Department of Nuclear Medicine and Radiobiology, Centre de Recherche du CHUS, Université de Sherbrooke, Sherbrooke, QC, Canada

The demonstration of metabolically active brown adipose tissue (BAT) in humans primarily using positron emission tomography coupled to computed tomography (PET/CT) with the glucose tracer 18-fluorodeoxyglucose ( ${ }^{18} \mathrm{FDG}$ ) has renewed the interest of the scientific and medical community in the possible role of BAT as a target for the prevention and treatment of obesity and type 2 diabetes (T2D). Here, we offer a comprehensive review of BAT energy metabolism in humans. Considerable advances in methods to measure BAT energy metabolism, including nonesterified fatty acids (NEFA), chylomicron-triglycerides (TG), oxygen, Krebs cycle rate, and intracellular TG have led to very good quantification of energy substrate metabolism per volume of active BAT in vivo. These studies have also shown that intracellular TG are likely the primary energy source of BAT upon activation by cold. Current estimates of BAT's contribution to energy expenditure range at the lower end of what would be potentially clinically relevant if chronically sustained. Yet, ${ }^{18}$ FDG PET/CT remains the gold-standard defining method to quantify total BAT volume of activity, used to calculate BAT's total energy expenditure. Unfortunately, BAT glucose metabolism better reflects BAT's insulin sensitivity and blood flow. It is now clear that most glucose taken up by BAT does not fuel mitochondrial oxidative metabolism and that BAT glucose uptake can therefore be disconnected from thermogenesis. Furthermore, BAT thermogenesis is efficiently recruited upon repeated cold exposure, doubling to tripling its total oxidative capacity, with reciprocal reduction of muscle thermogenesis. Recent data suggest that total BAT volume may be much larger than the typically observed $50-150 \mathrm{ml}$ with ${ }^{18} \mathrm{FDG}$ PET/CT. Therefore, the current estimates of total BAT thermogenesis, largely relying on total BAT volume using ${ }^{18} \mathrm{FDG}$ PET/CT, may underestimate the true contribution of BAT to total energy expenditure. Quantification of the contribution of BAT to energy expenditure begs for the development of more integrated whole body in vivo methods.

Keywords: brown adipose tissue, energy metabolism, obesity, type 2 diabetes, molecular imaging, positron emission tomography, tracer methods 


\section{INTRODUCTION}

Since 1980, the global prevalence of obesity has doubled (1). In 2015, overweight and obesity accounted for 4 million deaths worldwide, including 3.3 million from cardiovascular diseases and type 2 diabetes (T2D) (1). Restricting energy intake by reducing food consumption, increasing satiety and/or fat malabsorption, is the chief weight-loss mechanism of most medical and surgical treatments of obesity and has profound anti-diabetic effects (2-5). Increasing exercise- and non-exercise activity-related thermogenesis is the other cornerstone of obesity and T2D management. Simultaneously targeting multiple mechanisms of energy homeostasis is advantageous for the treatment of obesity (6). However, targeting energy expenditure unrelated to physical activity remains largely underexplored. Consequently, a number of unexploited mechanism may help fill a gap as an adjunct to current treatments for obesity and T2D.

One emerging, highly modifiable homeostatic mechanism for energy expenditure in humans is BAT thermogenesis. BAT may contribute as much as $60 \%$ of "non-shivering" thermogenesis in small mammals $(7,8)$, enabling their survival in the cold without reliance on shivering to produce heat $(9,10)$. BAT is currently considered a prime target for the treatment of obesity and T2D (11-15). Although the relative role of BAT on energy expenditure, thermogenesis and substrate utilization is dominant in rodents, the contribution of BAT to energy homeostasis in humans is more controversial. A detailed discussion on the different factors implicated in BAT and WAT "browning" such as immune cell-mediated modulation of adipose tissue sympathetic innervation (16) [please see (17) and (18) for review] is beyond the scope of the present review. The aim of the present article is to review the evidence for a role of BAT in energy substrate metabolism and thermogenesis in humans.

\section{THE DEFINITION OF BAT}

BAT is a heat-producing adipose tissue located in interscapular, subscapular, axillary, perirenal, and periaortic regions in rodents (19). In infants, the predominant interscapular distribution found in small mammals also occurs (20-22), but regresses with age and is lost at adulthood. The typical supraclavicular and paravertebral BAT distribution seen in adults appears to develop with puberty in boys and girls $(23,24)$. BAT cells differ from white adipose tissue (WAT) cells $(25,26)$. The former cells contain numerous small lipid vacuoles and a large number of welldeveloped mitochondria, whereas the latter are characterized by a single large lipid vacuole and a few mitochondria. BAT cells in WAT depots, called "beige" or "brite" adipocytes, have also been shown in rodents and humans (26). Histologically, "beige" cells demonstrate an intermediate phenotype between classical BAT adipocytes and classical white adipocytes (26).

The hallmark of BAT cells at the molecular level in animals and humans alike is the high level of expression of uncoupling protein-1 (UCP1). UCP1 is found in the inner membrane of BAT cells' mitochondria $(19,27)$. UCP1 uncouples mitochondrial respiration from adenosine-5'-triphosphate (ATP) synthesis (28). When activated, it causes a leak that dissipates the electrochemical proton gradient that builds up across the inner mitochondrial membrane during BAT fatty acid oxidation. This electrochemical proton gradient drives the conversion of adenosine- $5^{\prime}$-diphosphate (ADP) to ATP by ATP synthase. As a consequence, the presence of active UCP1 abolishes the negative feedback inhibition exerted by high ATP and/or low ADP levels on mitochondrial Krebs' cycle and respiration, leading to very high rate of fatty acid oxidation that directly produces heat. Because of its large amount of active UCP1 proteins, BAT is thus the only organ that literally can "burn" fat.

UCP1 is activated by long chain fatty acids $(19,28,29)$, but the mechanism by which it uncouples mitochondrial respiration has long been debated (30-32). UCP1 is an anion/ $\mathrm{H}^{+}$symporter that binds avidly long chain fatty acids, making it in effect a proton translocator (33). BAT is richly innervated by sympathetic nervous system efferent fibers and sympathetic activation is the physiological activator of BAT thermogenesis (19, 34-37). The release by these fibers of noradrenaline stimulates BAT intracellular triglyceride (TG) lipolysis, releasing long chain fatty acids that in turn activate UCP1 and BAT thermogenesis (Figure 1). We provided in vivo experimental evidence for this model by showing that nicotinic acid administration, an inhibitor of intracellular TG lipolysis, blocks acute coldstimulated BAT thermogenesis in rats (38) and in humans (39). Recent investigations using genetic deletion of genes essential for intracellular TG lipolysis in mice models have, however, casted doubt about the essential role of intracellular TG lipolysisderived fatty acids to activate BAT thermogenesis $(40,41)$. However, direct in vivo assessment of BAT thermogenesis was not measured and BAT of these genetic mouse models displayed a large increase in utilization of circulating fatty acids and glucose. It is therefore likely that intracellular TG and, if the later are unavailable circulating fatty acids, play an important role for the activation of BAT thermogenesis.

It is clear that BAT cells can stem from different cell lineages and display different molecular signatures depending on whether they are harvested from classical BAT or classical WAT depots (42-45). This molecular signature of supraclavicular BAT depots in humans may also be much more similar to that of "beige" adipocytes than that of "classical BAT" of rodents (46). Despite these differences, UCP1 content and function appear similar between human and mouse BAT (47). The distinct molecular signature of BAT could potentially be exploited for the in vivo identification and quantification of BAT. For example, targeting of a relatively BAT specific molecule, programed death ligand-1, was recently proposed for PET imaging and to quantify BAT in mice (48). However, from an integrative physiology and clinical perspective, it is the unique thermogenic potential of BAT, not its molecular signature, that matters. The presence of BAT in human adults has been noticed earlier from pathological investigations (49-51). Despite this early pathological description, the presence of functional BAT in adult humans was widely acknowledged only with the use of positron emission tomography coupled with computed tomography (PET/CT) with the glucose analogue 18 -fluoro-deoxyglucose $\left[{ }^{18} \mathrm{FDG}\right)(52-57)$. It is the very intense metabolic activity of otherwise metabolically quiescent fat tissue, at least with regards to glucose metabolism, that led the scientific 


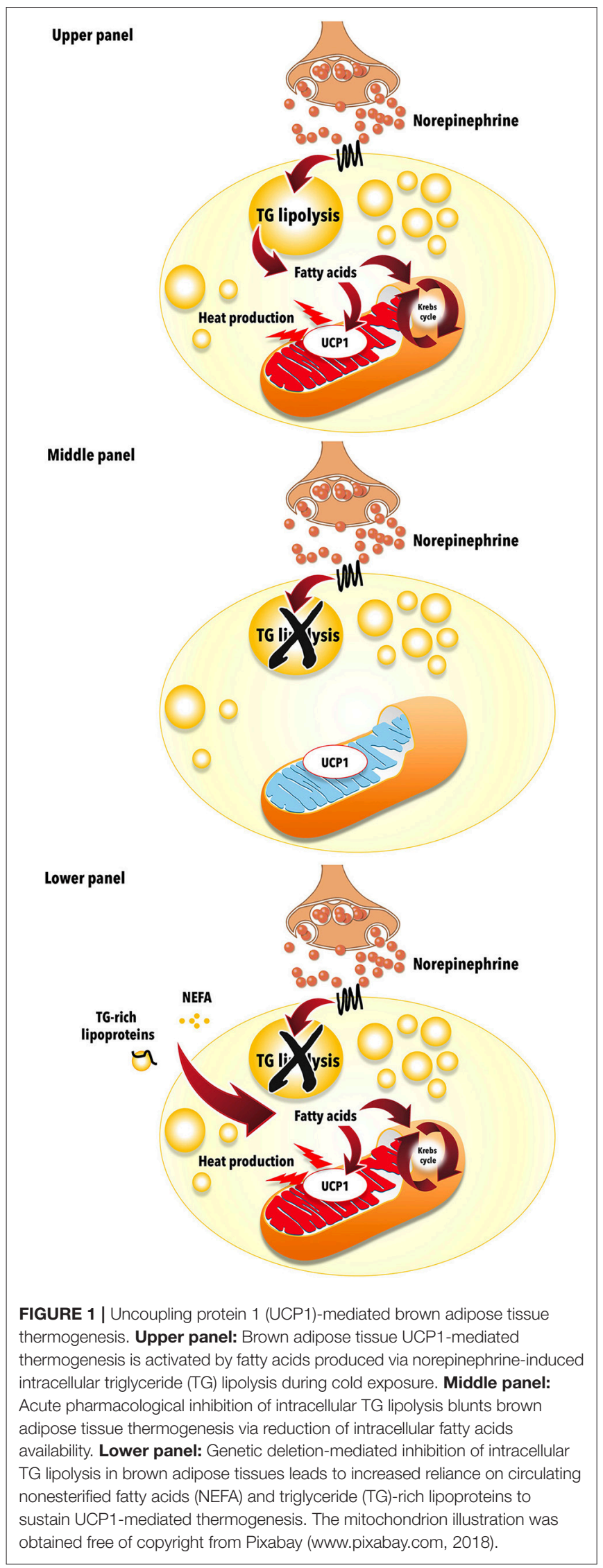

community to finally acknowledge BAT as an organ of interest for energy balance and as a potential therapeutic target for obesity and $\mathrm{T} 2 \mathrm{D}$.

Currently, ${ }^{18} \mathrm{FDG}$ PET/CT is considered the "gold-standard" method to identify BAT in humans (58), although BAT glucose metabolism does not accurately reflect BAT thermogenic activity (see section on glucose metabolism below) (59). The presence of BAT is defined according to the combination of two tissue characteristics on static (whole body) ${ }^{18} \mathrm{FDG}$ PET/CT acquisition (Figure 2): (1) unusually high ${ }^{18} \mathrm{FDG}$ (glucose) uptake for an adipose tissue, i.e., ${ }^{18}$ FDG PET standard uptake value normalized for lean mass higher than that of the upper range normally seen in classical WAT; and (2) a tissue radio-density on CT that is compatible with the presence of adipose tissue. Using ${ }^{18} \mathrm{FDG}$ PET/CT, most of the glucose-utilizing BAT volume ( ${ }^{(18} \mathrm{FDG}$ positive fat") is constituted by multiple small adipose depots scattered in the supraclavicular, paravertebral, pericardial, and suprarenal regions $(54,56,57,60)$. Using ${ }^{18} \mathrm{FDG} \mathrm{PET} / \mathrm{CT}$, measured BAT volume in humans varies over two orders of magnitude, from a few to hundreds of milliliters (59). Threedimensional mapping of adipose tissue depots with ${ }^{18} \mathrm{FDG}$ PET/CT showed that up to $4.3 \%$ of total body adipose tissue mass accounts for depots that may display significant glucose uptake upon cold exposure (61). However, the proportion of this adipose tissue mass that was demonstrated as BAT mass using ${ }^{18} \mathrm{FDG}$ PET/CT is very small, especially in obese individuals. It is important to note that accurate quantification of total BAT volume of metabolic activity by the addition of numerous small regions, typically less than $1 \mathrm{~cm}^{3}$ each, is very challenging using PET for a number of technical reasons that were discussed in more details elsewhere $(59,62) .{ }^{18} \mathrm{FDG}$ positive fat sites are also determined by a series of environmental and biological factors including outdoor temperature preceding PET/CT scanning procedures, age, sex, body fat content, central adiposity, the presence of diabetes, circadian rhythm, and the use of some drugs such as $\beta$-adrenergic blockers $(54,55,60,63-70)$. The prevalence of spontaneously detectable ${ }^{18} \mathrm{FDG}$ positive fat sites range from 2 to $7 \%$ in large cohorts of patients evaluated for cancer, but reaches $70-100 \%$ during experimental cold exposure $(58,59)$. ${ }^{18} \mathrm{FDG}$ positive BAT volume and/or activity also significantly increases within weeks of cold acclimation (71-74). Glucose uptake in BAT is profoundly influenced by insulin sensitivity (see section on glucose metabolism below). Because of these technical and biological reasons, ${ }^{18}$ FDG PET/CT therefore likely underestimates true BAT volume in humans, especially in people with obesity and T2D.

Despite emerging methods using other PET tracers $(48,75-$ $79)$, single-photon emission computed tomography $(67,80)$, magnetic resonance imaging (MRI), and spectroscopy (MRS) (81-89), near infrared spectroscopy $(90,91)$, contrast ultrasound (92), microwave radiometry (93), and optoacoustic imaging (94), ${ }^{18} \mathrm{FDG}$ PET/CT currently remains the best method to define the presence and to measure BAT volume in humans (95-98) (99). The lack of a method that directly measure total BAT volume and BAT-specific thermogenesis, however, constitutes an important gap to fill in order to accurately define the true contribution of BAT to energy homeostasis in humans. 


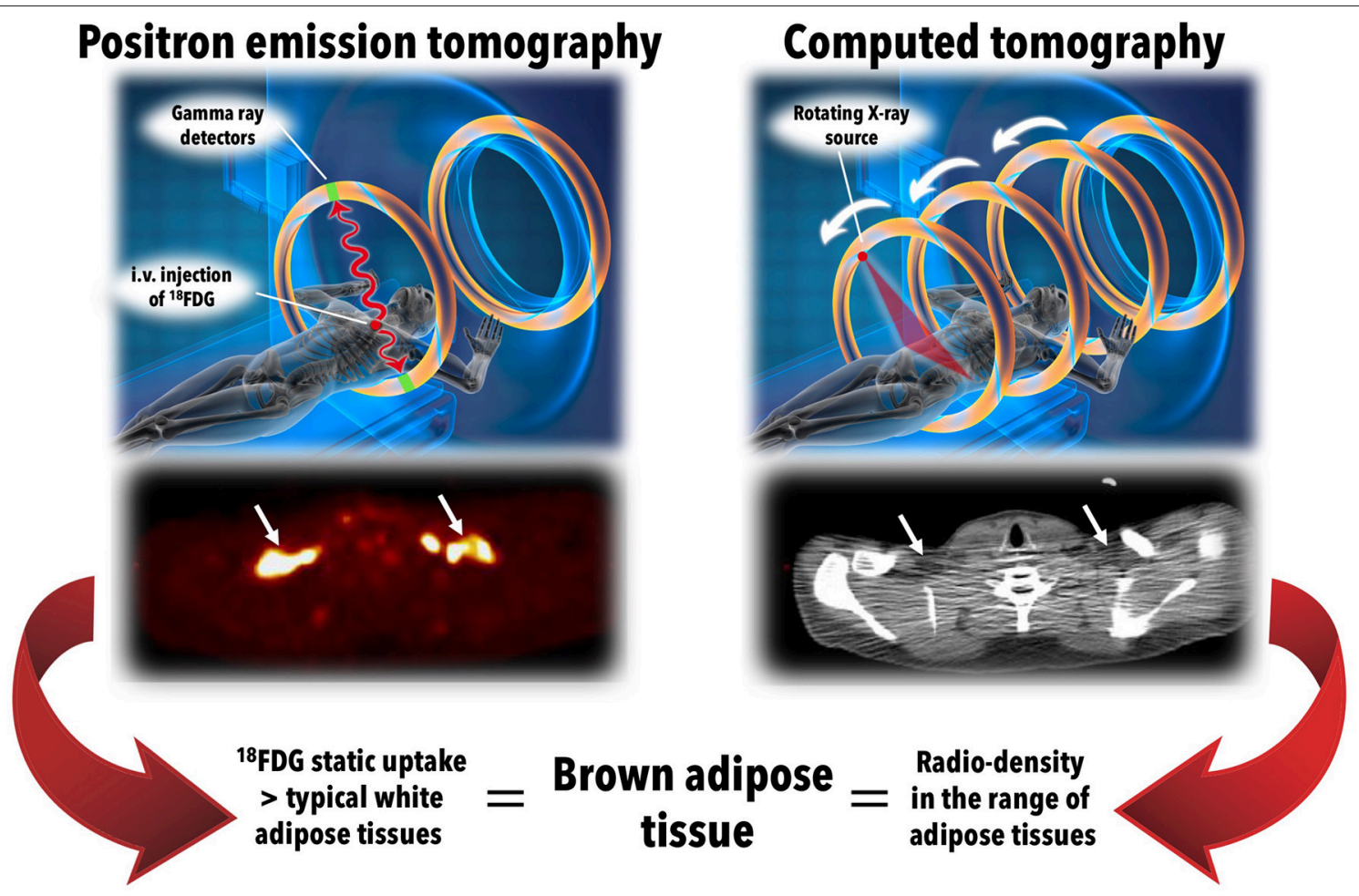

FIGURE 2 | The standard definition of brown adipose tissue in vivo in humans. Brown adipose tissue is currently defined in vivo in humans by the combination of two radiological features: (1) 18-fluorodeoxyglucose ( $\left.{ }^{18} \mathrm{FDG}\right)$ uptake above a set threshold higher than that usually observed in white adipose tissues using positron emission tomography (left panels); and (2) a radio-density that is compatible with the presence of adipose tissue using computed tomography (right panels). After intravenous (i.v.) injection of ${ }^{18} \mathrm{FDG}$, whole body (static) positron emission tomography scanning is performed, giving quantitative tissue bio-distribution of the tracer into brown adipose tissues. This tissue tracer uptake is co-registered with tissue radio-density measured using computed tomography. The middle left and right panels show positron emission tomography and computed tomography transverse views, respectively, of supraclavicular brown adipose tissue in a healthy individual during a standardized cooling protocol. Source of illustration: Shutterstock (www.shuterstock.com, 2018, no. 100687138).

\section{ENERGY SUBSTRATES UTILIZATION BY BAT}

\section{Glucose}

The demonstration of large increase in BAT glucose uptake with the activation of BAT oxidative metabolism led to the suggestion that BAT metabolic activation could be exploited to increase glucose clearance and utilization and treat diabetes $(100,101)$. This possibility was furthermore supported by recent epidemiological observations showing an association between increased glycosylated hemoglobin and increased incidence of diabetes with higher outdoor temperature $(68,102)$. Additionally, it was shown that the incidence of gestational diabetes rises by $6 \%$ for every $10^{\circ} \mathrm{C}$ increase in mean 30-day outdoor air temperature (103). Cold-induced whole body glucose disposal was shown to increase only in ${ }^{18}$ FDG BAT positive individuals (104) and BAT activation with cold exposure is furthermore associated with improved glucose homeostasis and insulin sensitivity in patients with T2D $(105,106)$.

There are, however, obvious problems with this hypothesis. First, cold exposure increases muscle glut4 cell membrane expression and stimulates shivering and deep muscle glucose uptake, even when care is applied to limit muscle shivering (105,
107). Therefore, this muscle metabolic activity likely contributes to some cold-induced increase in whole body glucose disposal. Second, although cold-induced BAT glucose uptake per volume of tissue is indeed usually higher than that of other tissues in healthy subjects $(107,108)$, total volume of ${ }^{18} \mathrm{FDG}$-positive BAT amounts to $<150 \mathrm{ml}$ in most healthy individuals (59). ${ }^{18} \mathrm{FDG}-$ positive BAT volume is also much smaller in individuals with obesity and T2D (109). This imposes an important limitation to the capacity of BAT metabolism to significantly impact systemic glucose clearance. For example, using whole body ${ }^{18}$ FDG PET acquisitions during standardized cold exposure in healthy subjects, we showed that BAT accounted for $\sim 1 \%$ of total body glucose utilization as compared to $\sim 50 \%$ for skeletal muscles (107) (Figure 3). Based on calculations that we previously described (110), glucose partitioning was $4,8,6$, and $10 \%$ in the heart, liver, visceral WAT, and sub-cutaneous WAT, respectively (Figure 4).

Unfortunately, dynamic ${ }^{18}$ FDG PET acquisition allowing precise quantification of BAT glucose uptake rate has been used by only a few investigators. The group of University of Turku in Finland has reported BAT glucose uptake rates during acute cold exposure in the order of $90-120 \mathrm{nmol} \cdot \mathrm{g}^{-1} \cdot \mathrm{min}^{-1}$ in healthy individuals and of $35 \mathrm{nmol} \cdot \mathrm{g}^{-1} \cdot \mathrm{min}^{-1}$ in obese 


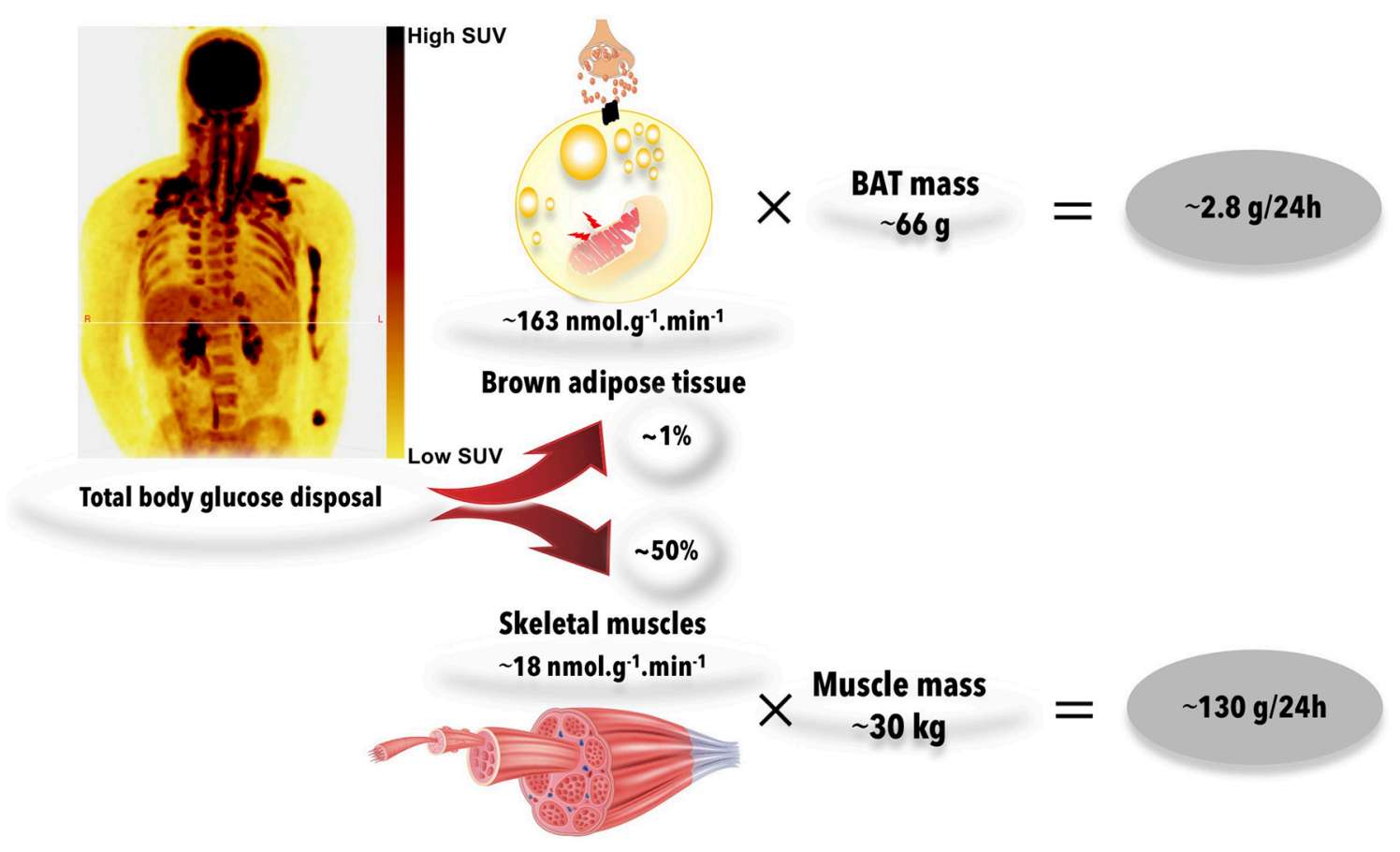

FIGURE 3 | Whole body glucose uptake into brown adipose tissues and muscles during acute cold exposure. During mild cold exposure, glucose uptake is stimulated in brown adipose tissue, but also in several centrally-located skeletal muscles. Brown adipose tissue glucose uptake is 8-fold higher than that of skeletal muscles, on average, per gram of tissue during mild cold exposure. However, total mass of brown adipose tissue is about $0.2 \%$ of that of skeletal muscles. Therefore, brown adipose tissue and skeletal muscle glucose uptake account for $\sim 1$ and $50 \%$, respectively, of systemic glucose disposal. The figures presented were calculated from previously published data in young healthy individuals, before cold acclimation (39). BAT, brown adipose tissue; SUV, standard uptake value. Source of muscle illustration: Shutterstock (www.shuterstock.com, 2018, no. 404668558).

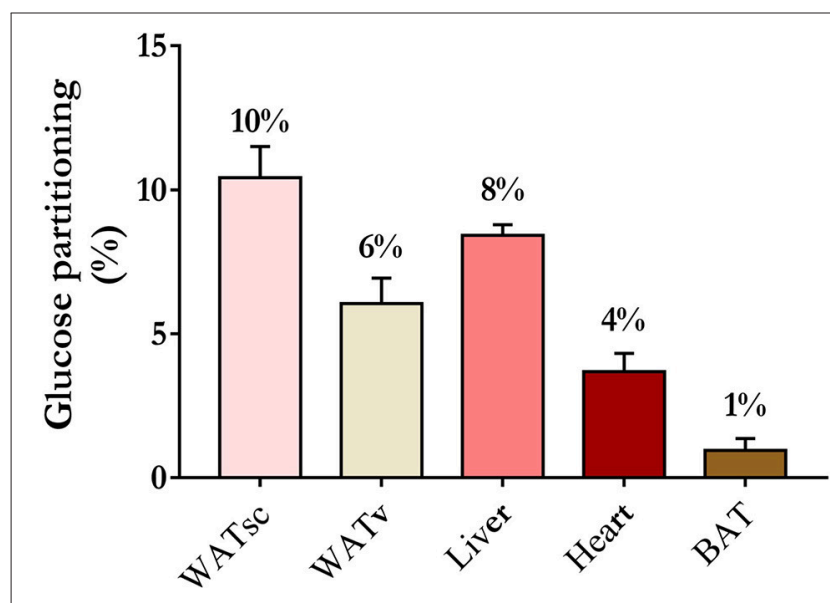

FIGURE 4 | Organ-specific glucose partitioning during acute cold exposure. The figures presented were calculated from a previously published study in young healthy individuals, before cold acclimation (39), based on calculations that we detailed previously (110). BAT, brown adipose tissue; WATsc,

sub-cutaneous white adipose tissues; WATv, visceral white adipose tissue.

individuals $(57,111,112)$. Our group at Université de Sherbrooke reported BAT glucose uptake rates during acute cold exposure at fasting ranging from $80 \pm 14 \mathrm{nmol} \cdot \mathrm{g}^{-1} \cdot \mathrm{min}^{-1}$ in non-coldacclimated healthy individuals to $209 \pm 50 \mathrm{nmol} \cdot \mathrm{g}^{-1} \cdot \mathrm{min}^{-1}$ in cold-acclimated healthy individuals (39, 73, 108) (Figure 5 and Table 1). We found BAT glucose uptake during cold exposure in the postprandial period in the range of $50 \mathrm{nmol} \cdot \mathrm{g}^{-1} \cdot \mathrm{min}^{-1}$, i.e., not very different from those measured in the fasting state (115). Although these rates of glucose uptake are two to threefold higher per volume of tissue than that measured in skeletal muscles, the much larger muscle vs. BAT mass translates into organ-specific uptake that is two orders of magnitude higher in the former (39). Furthermore, we found BAT glucose uptake rates to be much lower in older, overweight subjects without or with T2D, in the range of $\sim 10 \mathrm{nmol} \cdot \mathrm{g}^{-1} \cdot \mathrm{min}^{-1}$ (109). In absolute terms, we found rates of BAT glucose uptake ranging from $\sim 0.1 \mu \mathrm{mol} / \mathrm{min}$ in overweight individuals without and with $\mathrm{T} 2 \mathrm{D}$ to $\sim 3 \mu \mathrm{mol} / \mathrm{min}$ in healthy individuals during acute cold exposure. Using simultaneous quantification of BAT glucose uptake with dynamic ${ }^{18}$ FDG PET acquisition and systemic glucose utilization with conventional glucose tracer method, we found that acutely cold-activated BAT glucose uptake accounted for $<1 \%$ of systemic glucose turnover in healthy men $(39,108$, 109). It is therefore unlikely that BAT activation may significantly contribute to improve systemic glucose metabolism, especially in subjects with impaired glucose metabolism.

BAT glucose uptake has been extensively used as a surrogate marker of BAT thermogenesis in humans on the basis of correlative observations between BAT thermogenic activity and glucose uptake. Indeed, the presence and metabolic activity 

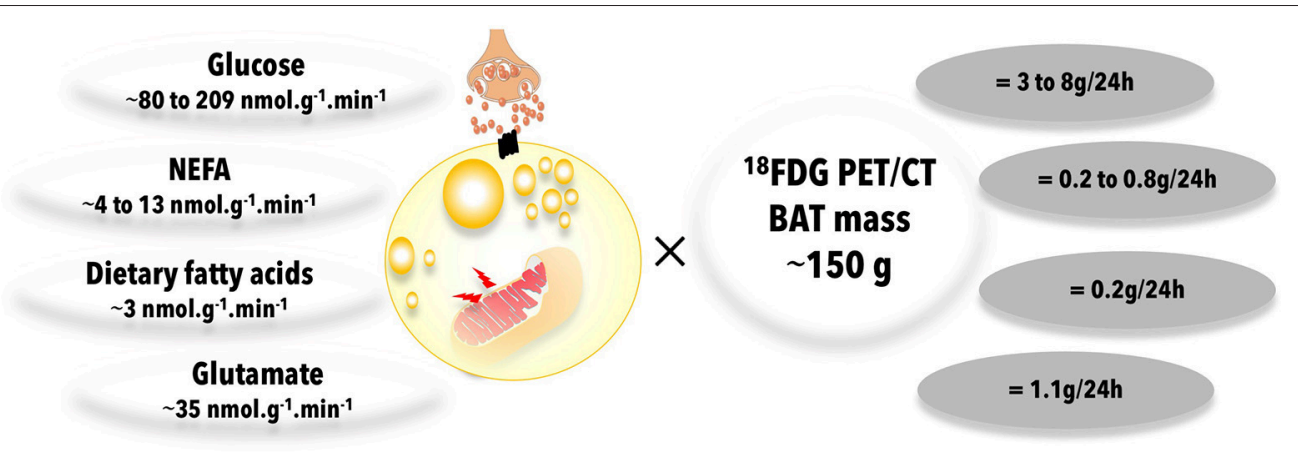

BAT uptake per mass

FIGURE 5 | Brown adipose tissue uptake of energy substrates. Total brown adipose tissue uptake of energy substrates is calculated from published quantitative, dynamic positron emission tomography or microdialysis experiments in humans, multiplied by a typical total brown adipose tissue mass reported in the literature. Data from $(73,108,113),(108,113,114),(115)$, and (116) were used to calculate glucose, NEFA, dietary fatty acid, and glutamate BAT uptake, respectively. ${ }^{18}$ FDG, 18-fluorodeoxyglucose; BAT, brown adipose tissue; NEFA, nonesterified fatty acids; PET/CT, positron emission tomography coupled with computed tomography.

TABLE 1 | Upper and lower estimates of brown adipose tissue plasma glucose, nonesterified fatty acid, dietary fat, and glutamate uptake rates in humans.

\begin{tabular}{|c|c|c|c|c|c|}
\hline Substrate & $\begin{array}{l}\text { Mean uptake } \\
\left(\mathrm{nmol} \cdot \mathrm{g}^{-1} \cdot \mathrm{min}^{-1}\right)\end{array}$ & $\begin{array}{c}\text { Molar mass } \\
(\text { g.mol }\end{array}$ & $\begin{array}{l}\text { Absolute uptake } \\
\text { assuming BAT mass } \\
\text { of } 150 \mathrm{~g}\left(\mathrm{~g} \mathrm{day}^{-1}\right)\end{array}$ & Notes & References \\
\hline Glucose & 209 & & 8.13 & Healthy men, post-cold acclimation, acute cold exposure & (73) \\
\hline \multirow[t]{2}{*}{ NEFA } & 4 & 275.446 & 0.24 & Obese subjects, room temperature & (114) \\
\hline & 13 & & 0.77 & Healthy men, acute cold exposure & $(108,109)$ \\
\hline Glutamate & 35 & 147.13 & 1.11 & Healthy men, acute cold exposure & $(116)$ \\
\hline
\end{tabular}

NEFA, nonesterified fatty acids.

of ${ }^{18}$ FDG positive BAT are associated with increased plasma catecholamines and inversely related to central obesity in patients with pheochromocytoma (117). Cold-induced BAT glucose uptake correlates with BAT sympathetic activity in vivo (118) and unilateral sympathetic denervation has been shown to reduce supraclavicular BAT glucose uptake in a patient (119). In mice however, $\beta 3$-adrenergic-stimulated BAT glucose uptake does not need the presence of UCP1 and activation of BAT thermogenesis $(120,121)$. Extrapolated over a $24 \mathrm{~h}$ period, BAT glucose uptake in healthy individuals in our hands sums up only to a maximum utilization of $5 \mathrm{~g}$ of glucose, or $\sim 23 \mathrm{kcal}$. Obviously, this energy expenditure rate assumes that BAT fully oxidizes the glucose it takes up. The classical studies by Ma and Foster (122), however, demonstrated more than three decades ago that a large fraction of glucose taken up by BAT is metabolized and released as lactate or serves for glyceroneogenesis (123) or perhaps de novo lipogenesis and does not contribute to increased BAT oxidative metabolism (Figure 6). Activated BAT glucose uptake exceeds increase in blood flow, suggesting non-thermogenic utilization of glucose by BAT in humans (124). A recent study using the adipose tissue microdialysis technique applied to supra-clavicular BAT also demonstrated that a large fraction of glucose taken up by BAT upon acute cold exposure is released as lactate in vivo in healthy subjects (116). The later study also independently confirmed the magnitude of glucose uptake in BAT measured by the ${ }^{18}$ FDG PET dynamic acquisition method. Thus, glucose uptake is not a good method to quantify BAT oxidative metabolism and thermogenesis, even in healthy subjects.

${ }^{18}$ FDG BAT positive individuals are more insulin sensitive and cold-induced BAT glucose uptake and stimulation of blood flow are blunted in obese individuals (112). BAT glucose uptake is reduced with genetic variants associated with insulin resistance (125), glucocorticoid treatment (126), fasting-induced insulin resistance (127). Chronic ephedrine administration which may induce insulin resistance leads to reduced BAT glucose uptake despite increased weight loss (128). BAT glucose uptake tends to be higher after bariatric surgery-induced weight loss in obese individuals $(129,130)$. Exercise, which increases muscle glucose uptake and improves whole body insulin sensitivity, does not however necessarily lead to increase in insulinmediated BAT glucose uptake (131). Insulin stimulates BAT glucose uptake without stimulating blood flow, suggesting that insulin signaling increases BAT glucose uptake independent of BAT thermogenic activation (111). We found that older, overweight individuals without and with T2D display a $\sim 10$ fold reduction in BAT glucose uptake rate vs. young healthy 


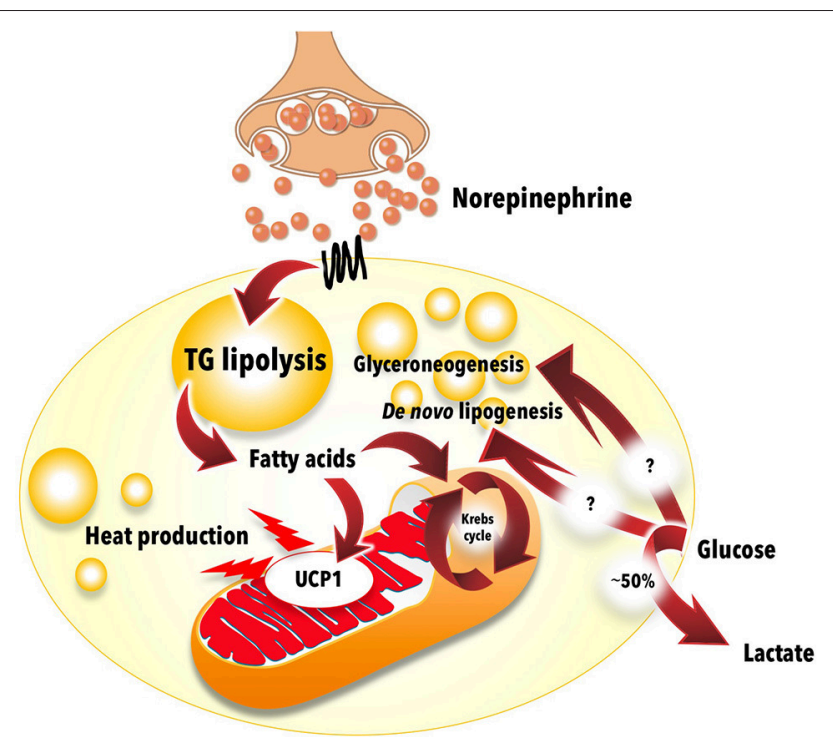

FIGURE 6 | Glucose metabolism in brown adipose tissue. Most of the glucose taken up by brown adipose tissue during cold exposure does not contribute to thermogenesis. Experimental data show that approximately half of the glucose molecules are excreted from brown adipose tissue as lactate. Most of the remaining glucose likely contributes to glycerol production (glyceroneogenesis) and/or fatty acid synthesis (de novo lipogenesis) for intracellular triglyceride synthesis. The mitochondrion illustration was obtained free of copyright from Pixabay (www.pixabay.com, 2018).

subjects despite no reduction in BAT NEFA uptake and thermogenic activity upon acute cold exposure (109). Reduced BAT glucose uptake is furthermore associated with increased BAT fat content $(88,109,132)$. Thus, as in lean tissues and WAT (133), excess lipid deposition appears to be a marker of BAT insulin resistance. Total BAT volume of ${ }^{18}$ FDG uptake has been associated with plasma NEFA appearance rate and oxidation and with WAT insulin sensitivity during cold exposure $(109,134)$. Thus, BAT glucose uptake may be a marker of WAT metabolic flexibility. In the presence of obesity, T2D or other insulin resistance states, BAT glucose uptake is an especially poor surrogate marker for BAT thermogenic activity.

Typical BAT cells expressing UCP1, large mitochondrial content and numerous small lipid vacuoles are present in supraclavicular adipose depots, independent of the presence of spontaneously active BAT based on ${ }^{18}$ FDG PET (135). Because ${ }^{18} \mathrm{FDG}$ PET/CT is currently the only method capable of measuring BAT volume of metabolic activity, the above considerations clearly point to the absence of a reliable method to quantify BAT volume and, therefore, total thermogenic activity in humans. Unfortunately, all of the figures thus far reported with regards to the contribution of BAT to fatty acid utilization and whole body thermogenesis (see below) have been calculated using total BAT volume from ${ }^{18} \mathrm{FDG}$ PET/CT. Therefore, these figures are likely underestimated, especially in subjects with any degree of insulin resistance.

\section{Circulating Fatty Acids}

Utilization of circulating fatty acids by BAT may occur through two different pools in circulation: (1) NEFA; and (2) triglyceriderich lipoproteins (TRL). Plasma NEFA are produced mostly by WAT, either via intracellular TG lipolysis or via LPLmediated lipolysis of circulating TRL (i.e., NEFA spillover of TRL into the systemic circulation) (136). The circulating NEFA pool is tightly regulated by the sympathetic system and circulating insulin level via $\beta$-adrenergic stimulation and insulin signaling-mediated inhibition, respectively, of intracellular WAT lipolysis. Although plasma membrane fatty acid transporters (137) and local blood flow (138) are known to modify local tissue NEFA uptake, tissue NEFA transport rate is mostly regulated by the plasma NEFA concentration and by the tissue's rate of fatty acid oxidation. TRL include: (1) chylomicrons, produced by the intestine and transporting dietary fatty acids into the circulation; and (2) VLDL, produced by the liver and transporting TG from NEFA and lipoprotein-derived fatty acids recycled in the liver and fatty acids produced de novo from carbohydrates in the liver (110, 139). These two TRL circulating pools are mostly regulated through clearance mainly mediated by the activity of LPL, although increase in liver's VLDL-TG secretion rate also contributes to the increase of TG in circulation with obesity and T2D. Local tissue uptake of fatty acids from circulating TRL is mostly under the control of local tissue LPL-mediated lipolysis (140).

As can be expected from stimulation of the sympathetic system activity, acute cold exposure leads to robust increase in plasma NEFA levels and appearance rate $(39,108,109,141)$. Upregulation of genes of lipid utilization was shown in BAT with cold exposure in humans (134). Only a few studies however reported BAT-specific uptake rates of plasma NEFA. In all instances, this has been performed using the PET tracer ${ }^{18} \mathrm{~F}$ fluoro-6-thiaheptadecanoic acid $\left[{ }^{18}\right.$ FTHA), a long-chain fatty acid analog that is taken up at similar rate than palmitate and that is trapped into the mitochondrial matrix and non-oxidative fatty acid metabolic pathways (142). These characteristics make this tracer, when administered intravenously, an excellent method to measure tissue-specific plasma NEFA uptake rate, but not tissue oxidative or non-oxidative metabolism. Using ${ }^{18}$ FTHA PET, BAT NEFA uptake was reported similar in healthy $(\sim 5.7$ nmol. $\left.\mathrm{g}^{-1} \cdot \mathrm{min}^{-1}\right)$ and obese subjects $\left(\sim 3.9 \mathrm{nmol} \cdot \mathrm{g}^{-1} \cdot \mathrm{min}^{-1}\right.$, non-significant vs. healthy) at room temperature (Figure 5 and Table 1), only slightly higher than the NEFA uptake rate observed in subcutaneous neck WAT $\left(\sim 4.7\right.$ and $\sim 3.4 \mathrm{nmol} . \mathrm{g}^{-1} \cdot \mathrm{min}^{-1}$, respectively) (114). In the later study, slight but significant increase in BAT NEFA uptake rate was shown 6 months after bariatric surgery in obese individuals $\left(\sim 5.0 \mathrm{nmol} . \mathrm{g}^{-1} \cdot \mathrm{min}^{-1}\right)$ (114). Interestingly, BAT NEFA uptake was inversely correlated with age, waist circumference and percent body fat and directly correlated with HDL cholesterol level (114). Using ${ }^{18}$ FTHA PET, we reported BAT NEFA uptake rates $\sim 13 \mathrm{nmol} . \mathrm{g}^{-1} . \mathrm{min}^{-1}$ in healthy young men acutely exposed to cold $(108,109)$ (Figure 5 and Table 1). We found BAT NEFA uptake in the same range as that observed in skeletal muscles and two to three-fold higher than that of subcutaneous WAT of the neck. In contrast to 
glucose uptake, BAT NEFA uptake per volume of tissue was the same in older, overweight participants without or with T2D compared to healthy young men (109). Because of the overlap in NEFA uptake between BAT and WAT and the limited experience with ${ }^{18}$ FTHA PET for BAT imaging, it has been thus far impossible to use this method to measure BAT volume, as performed using ${ }^{18}$ FDG PET/CT. Thus, current estimates of BAT total contribution to NEFA uptake is limited by the use of ${ }^{18} \mathrm{FDG}$ $\mathrm{PET} / \mathrm{CT}$ to measure BAT volume. Using the latter, we calculated that BAT may metabolize $\sim 7 \mu$ mol. $\mathrm{min}^{-1}$ of plasma NEFA in healthy men exposed to cold, but only $0.1 \mu \mathrm{mol} \cdot \mathrm{min}^{-1}$ in older overweight subjects without or with T2D (109). Extrapolated over a 24 -h period, this amounts to up to $0.6 \mathrm{~g}$ of fat, or $<3$ $\mathrm{kcal}$. Using simultaneous intravenous stable isotopic palmitate tracer, we calculated that BAT contribution to whole body NEFA metabolism is $<1 \%(108,109)$. Given the likely underestimation of BAT volume using ${ }^{18}$ FDG PET/CT, however, it is possible that BAT contribution to plasma NEFA metabolism could be higher. Cold-induced BAT NEFA uptake was shown to be associated with BAT thermogenesis (143). Therefore, the use of BAT NEFA uptake as a surrogate of BAT thermogenesis remains a viable alternative to glucose uptake. However, the use of PET NEFA tracers that can measure tissue oxidative and non-oxidative metabolic rates, as for example ${ }^{11} \mathrm{C}$-palmitate, will be needed to ensure that BAT NEFA uptake is quantitatively linked to BAT oxidative metabolism and not fatty acid esterification into BAT TG droplets.

Animal studies showing that activated BAT utilizes a large fraction of circulating TRL led to the hypothesis that active BAT may reduce circulating lipoprotein-TG and cholesterol in humans $(144,145)$. Angiopoietin-like 4 (ANGPTL4) is downregulated in BAT during cold exposure in mice, leading to LPL-stimulated TG lipolysis and fatty acid uptake in BAT (146). Activated BAT in mice stimulates the formation of lipoprotein remnants from more buoyant TRL (147). Thus, in rodents, metabolically active BAT exerts significant impact on circulating TRL metabolism. Lower plasma TG and increased HDL-c has been observed in subjects with metabolically active BAT determined by ${ }^{18}$ FDG PET/CT (148). Experimental acute cold exposure in humans does not however lead to significant reduction in plasma TG levels $(108,109)$ and may even lead to small increase in TG and cholesterol levels in some instances $(106,141)$. To our knowledge, we published the only study that measured directly BAT uptake of fatty acids transported by TRL in humans (115). To achieve this, we used the oral ${ }^{18}$ FTHA PET method that we validated to measure organ-specific dietary fatty acid uptake (149). This method measures relative tissue uptake (partitioning) of dietary fatty acids from direct transport through chylomicron-TG and recycling from WAT metabolism as NEFA [see our recent review for a detailed discussion on the method (110)]. We demonstrated significant, albeit small, BAT dietary fatty acid uptake after administration of a standard meal during acute cold exposure in healthy young men (115). Rate of BAT dietary fatty acid uptake was calculated at $\sim 3 \mathrm{nmol} . \mathrm{g}^{-1} \cdot \mathrm{min}^{-1}$ (Figure 5 and Table 1), two to three-fold higher than in the neck subcutaneous WAT and skeletal muscles, respectively. Because of the small BAT volume, again determined using ${ }^{18} \mathrm{FDG}$ PET/CT,
BAT only contributed to $0.3 \%$ of whole body dietary fatty acid partitioning. In contrast to what has been observed in mice (144), BAT contribution's to whole body dietary fatty acid metabolism was much lower than that of the liver, the heart, skeletal muscles, and even WAT (115). Furthermore, we found that 4 -week cold acclimation that significantly increased BAT oxidative metabolism in the participants did not increase BAT dietary fatty acid uptake (115). There was no relation between BAT oxidative metabolism and BAT dietary fatty acid uptake, suggesting that the latter is not a main energy substrate for BAT thermogenesis in humans, at least during acute cold exposure.

Cold-induced changes in plasma concentrations of some nonprominent fatty acids has been reported (106), but there was no demonstration that these changes were indeed due to increase in BAT metabolism. Cold exposure induces 12,13-dihydroxy9Z-octadecenoic acid production in BAT and in circulation, which in turn may contribute to stimulate BAT fatty acid uptake in mice (150). In a cross-sectional study in healthy men, lysophosphatidylcholine-acyl C16:1 was shown to correlate with BAT volume and metabolic activity assessed by ${ }^{18} \mathrm{FDG}$ PET/CT (151). The physiological and clinical relevance of these observations are unclear at the moment.

\section{Other Substrates in Circulation}

BAT expresses glycerol kinase at higher levels than WAT and thus has the potential to utilize glycerol (152). Furthermore, this enzyme's expression is increased in BAT by cold exposure and $\beta$-adrenergic stimulation $(153,154)$. Recent experiments in mice showed that glycerol kinase is a downstream target of $\operatorname{PPAR} \gamma$ and that its inhibition leads to reduced UCP1 expression, isoproterenol-stimulated cellular respiration and intracellular TG synthesis (155). A very recent study using adipose tissue microdialysis technique applied to supra-clavicular BAT in humans demonstrated reduced glycerol release by BAT vs. WAT at room temperature, suggesting that glycerol can be recycled to a greater extent in BAT compared to WAT (116).

Weir et al., using the microdialysis technique in supraclavicular BAT, reported significantly higher uptake of glutamate (i.e., $\sim 35 \mathrm{nmol} . \mathrm{g}^{-1} \cdot \mathrm{min}^{-1}$ ) by this tissue (Figure 5 and Table 1) vs. WAT (i.e., $\sim 12 \mathrm{nmol} . \mathrm{g}^{-1} \cdot \mathrm{min}^{-1}$ ) upon acute cold exposure (116). Uptake of glutamate in BAT, but not in WAT, was also significantly increased by acute cold exposure in the later study (by $\sim 10 \mathrm{nmol} \cdot \mathrm{g}^{-1} \cdot \mathrm{min}^{-1}$ ), suggesting the use of this substrate for energy production or, alternatively, for anaplerosis. However, cold-induced increase in glucose uptake was about 10 -fold (by $\sim 120 \mathrm{nmol} . \mathrm{g}^{-1} \cdot \mathrm{min}^{-1}$ ), showing that glutamate is a minor BAT substrate compared to glucose (116). Weir et al. also demonstrated net release of lactate $(\sim 150-200$ nmol. $\left.\mathrm{g}^{-1} \cdot \mathrm{min}^{-1}\right)$ and pyruvate $\left(\sim 5 \mathrm{nmol} \cdot \mathrm{g}^{-1} \cdot \mathrm{min}^{-1}\right)$ by BAT that increased non significantly with acute cold exposure (by $\sim 50$ and $\sim 1 \mathrm{nmol} . \mathrm{g}^{-1} \cdot \mathrm{min}^{-1}$, respectively) (116). This release of lactate and pyruvate accounted for approximately half of the glucose that was taken up by BAT in response to cold.

To our knowledge, there has been thus far no attempt to quantify BAT utilization rate of ketones or amino acids in vivo in humans. Based on cardiac utilization rate of these substrates (156), it is however unlikely that they amount to a significant 
proportion of energy substrate utilization compared to fatty acids and glucose under most physiological circumstances.

\section{Intracellular Triglycerides}

Intracellular TG content of BAT can be quantified using CT or magnetic resonance imaging and spectroscopy (MRI/MRS). The former technique, as applied currently by most groups in the field of research on brown adipose tissue, is semi-quantitative and can only provide relative content of lipids in a tissue by comparing its radio-density (quantified in Hounsfield units). MRS is the gold-standard method for non-invasive quantification of tissue triglycerides (as opposed to total lipid content) and directly reports TG vs. water content of a tissue (62). BAT CT radio-density is strongly correlated with \%TG by MRS (157). MRI can also provide quantitative fat-to-water ratios in BAT, that is lower than that observed in WAT (87). However, because of the large overlap observed in fat-to-water ratios, it is not possible to systematically distinguish metabolically active from non-active BAT or even WAT depots using quantification of adipose tissue fat fraction (158). These methods are sensitive enough to demonstrate association of fat fraction in BAT with biologically and clinically relevant end-points. For example, BAT fat fraction has been associated with systemic insulin resistance, central obesity or T2D $(109,114,159)$ and with BAT NEFA uptake (157). BAT fat fraction is also reduced in obese individuals 6 months after bariatric surgery and this reduction is associated with reduction in BMI and insulin resistance (114).

Early observation demonstrated that BAT radio-density increases rapidly during acute cold exposure in rats and humans (160). Numerous studies have now demonstrated that BAT TG content is hydrolyzed within $1-3 \mathrm{~h}$ through sympatheticallystimulated intracellular lipolysis, as observed using CT or MRI/MRS to monitor shifts of BAT water-to-fat ratio $(73,87$, $108,109,115,132,158,159,161)$. This reduction in BAT TG content during acute cold exposure is specific to BAT and does not occur in WAT or in shivering muscles (Figure 7). It has also been related to whole body insulin sensitivity (132) and with plasma NEFA appearance rate (109). However, in contrast to cold-stimulated BAT glucose uptake, the rapid cold-induced reduction of BAT intracellular TG content is independent of age and T2D status, at equivalent cold exposure (109).

Assuming a total body BAT mass of $168 \mathrm{~g}$ [our ${ }^{18} \mathrm{FDG}$ PET/CT data, (108)] and cold-induced reduction of BAT TG fraction from 81 to $76 \%$ (i.e., from 136 to $128 \mathrm{~g}$ of $\mathrm{TG}$ ) (132), $\sim 8 \mathrm{~g}$ of $\mathrm{TG}$ $(\sim 72 \mathrm{kcal})$ is mobilized from BAT over 2 hours of very mild cold exposure (Figure 7). In vitro experiments have suggested that up to $50 \%$ of fatty acids hydrolyzed by BAT could be released into the extracellular media (162) and subsequently oxidized or re-esterified elsewhere. It is therefore not possible to determine the precise contribution of fatty acids released by intracellular TG lipolysis to BAT thermogenesis currently, because the intracellular metabolic fate of fatty acids utilized by BAT has not yet been determined in vivo in humans. From BAT microdialysis data, glycerol release of BAT during cold exposure amounts to $\sim 22 \mathrm{nmol} . \mathrm{g}^{-1} \cdot \mathrm{min}^{-1}$ vs. $\sim 10 \mathrm{nmol} \cdot \mathrm{g}^{-1} \cdot \mathrm{min}^{-1}$ at room temperature (116). It is not possible to directly measure tissue fatty acid release using microdialysis, but assuming that 3 fatty acid molecules are produced from intracellular TG per molecule of glycerol released, this cold-induced glycerol release $(\sim 12$ nmol.g $\mathrm{g}^{-1} \cdot \mathrm{min}^{-1}$ ) could represent up to $\sim 36 \mathrm{nmol} . \mathrm{g}^{-1} \cdot \mathrm{min}^{-1}$ of fatty acids released by intracellular TG lipolysis in BAT. Assuming a fatty acid composition of $\sim 30$ palmitate, 30 linoleate, and $40 \%$ oleate (i.e., an average molar mass of 274.04 g.mol ${ }^{-1}$ ) (163), and an average BAT mass of $168 \mathrm{~g}$ (108), this would sum up to $2.4 \mathrm{~g}$ of fat over $24 \mathrm{~h}$, or $\sim 21 \mathrm{kcal}$. These figures, however, are likely underestimated given significant intracellular recycling of glycerol by BAT (116). Therefore, current estimates of fatty acid metabolism from BAT intracellular TG mobilization range between $\sim 3$ to up to $96 \mathrm{~g}$ over $24 \mathrm{~h}$ with sustained activation. Again, these figures depend on total BAT volume measured using ${ }^{18}$ FDG PET/CT and, therefore, are likely underestimated. It is also not known what proportion of these fatty acids are oxidized directly by BAT vs. released in circulation in vivo in humans.

We have shown in animals (38) and in humans (39) that BAT TG content is the primary source of energy that fuels BAT thermogenesis. We used nicotinic acid to inhibit intracellular BAT TG lipolysis in vivo, and to fully arrest BAT water-to-fat ratio shift and oxidative metabolism upon acute cold exposure. We also showed that blocking BAT thermogenesis with nicotinic acid reduced BAT glucose uptake by $26 \%$ (i.e., equivalent to $62 \mathrm{mg}$ of glucose over the course of the study), with no change in systemic glucose turnover (39). This reduction in glucose uptake was most likely due to the abolished cold-induced increase in BAT oxidative metabolism with nicotinic acid, since fatty acids from intracellular TG activate UCP1-mediated mitochondrial energy uncoupling $(19,28,29)$. Likewise, although not measured in our study, BAT NEFA uptake was likely also driven down by nicotinic acid-mediated inhibition of plasma NEFA appearance from WAT (39). Cold-stimulated BAT blood flow was unaffected by nicotinic acid, demonstrating that cold-induced water-to-fat ratio shift is indeed due to BAT TG disappearance, as opposed to increased blood flow. Importantly, muscle shivering rose reciprocally, compensating for the reduction in BAT thermogenesis. Given the small magnitude of the nicotinic acid-induced reduction of BAT glucose uptake and the currently estimated small contribution of plasma NEFA utilization by BAT in humans (see section Circulating fatty acids above), it is unlikely that these off-target effects of nicotinic acid confounded nicotinic acid effect through inhibition of intracellular TG lipolysis on BAT thermogenesis. In mice, gene deletion of key enzymes of BAT intracellular TG lipolysis induces a major increase in BAT utilization of fatty acids in circulation, thus substituting for BAT TG in order to sustain cold-induced thermogenesis $(40,41)$. In summary, these in vivo evidences suggest a major role for intracellular TG as fuel for BAT thermogenesis.

\section{CONTRIBUTION OF BAT TO THERMOGENESIS AND ENERGY EXPENDITURE}

Some indirect evidences suggest a significant role for BAT in cold-induced thermogenesis in humans. Cold-induced increase in whole body energy expenditure is related to the presence 

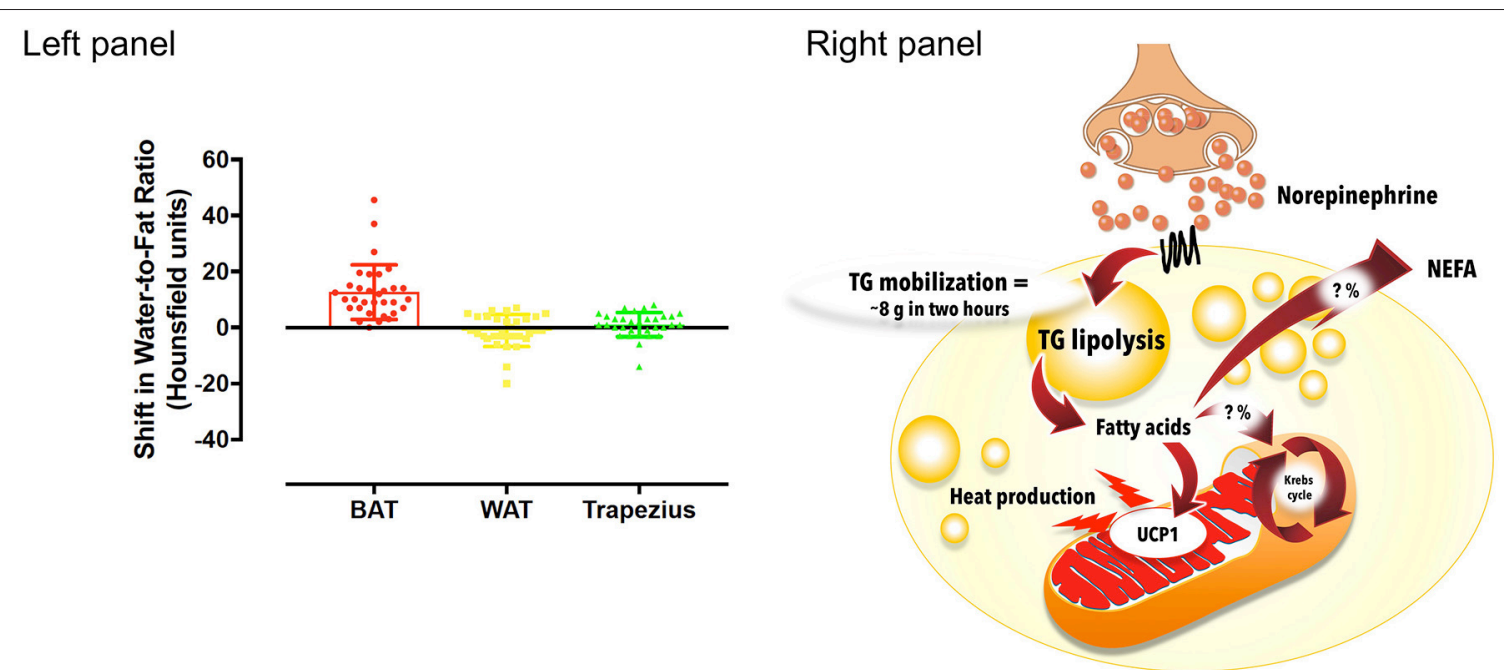

FIGURE 7 | Intracellular triglyceride (TG) mobilization in brown adipose tissue during cold exposure. Left panel: Brown adipose tissue (BAT), white adipose tissue (WAT) and trapezius muscle change in radio-density during standardized acute cold exposure from previously published studies of our group (39, 73, 108, 109). Right panel: During cold-induced brown adipose tissue metabolic activation, up to $8 \mathrm{~g}$ of intracellular triglycerides can be mobilized within $2 \mathrm{~h}$. The metabolic fate of the fatty acids that are mobilized is currently unknown. Although these fatty acids likely constitute most of the energy substrates driving brown adipose tissue thermogenesis, a fraction of them may also be released in circulation to be utilized by other tissues. NEFA, nonesterified fatty acids; UCP1, uncoupling protein 1. The mitochondrion illustration was obtained free of copyright from Pixabay (www.pixabay.com, 2018).

of ${ }^{18}$ FDG positive BAT (164, 165). Cold-stimulated BAT blood flow is also associated with cold-induced whole body energy expenditure (111) and is blunted in obesity (112). Seasonal variation of cold-induced whole body energy expenditure is larger in ${ }^{18} \mathrm{FDG}$ BAT positive subjects (166). Total ${ }^{18} \mathrm{FDG}$ BAT volume is correlated with higher core body temperature during experimental cooling procedures in one study (167). Living in a mildly cold environment increases energy expenditure and, using ${ }^{18}$ FDG PET, BAT activation was shown to be a significant determinant of this response (168). We found that inhibition of BAT thermogenesis using nicotinic acid administration leads to reciprocal increase in muscle shivering to combat cold, suggesting a physiologically significant role for BAT in cold-induced thermogenesis (39). We also reported increased skeletal muscle energy coupling with cold acclimation-which is expected to reduce heat production at the same shivering intensity-suggesting an important role for BAT thermogenesis during cold acclimation (113).

Other indirect evidences suggest a role for BAT in energy expenditure and caloric balance in humans. The presence of metabolically active BAT assessed using ${ }^{18} \mathrm{FDG}$ PET/CT is associated with reduced adiposity, especially with aging (56, 164, 169), with higher resting energy expenditure (56, 170), and with less ectopic fat deposition in the liver (171). Athletes, however, tend to have lower BAT volume and activity based on ${ }^{18}$ FDG PET/CT despite higher whole body energy expenditure (172, 173). UCP1 and beta-3 adrenergic receptor polymorphisms have been associated with lower BAT glucose metabolic activity and increased visceral fat with aging (174). Upstream stimulatory factor 1 deficiency that was shown to activate BAT metabolism in mice, is associated with improved insulin sensitivity, lipid profile and cardiometabolic risk in humans (175). Cold acclimation that increases BAT metabolic activity has been shown to reduce weight in some (72), but not all studies $(73,74,104,105,176)$. The presence of ${ }^{18}$ FDG PET BAT predicts capsinoids, catechin-, and caffeine-stimulated whole body energy expenditure $(177,178)$. Treatment with capsinoids leads to increased BAT glucose uptake and supraclavicular temperature determined by near-infrared spectroscopy (90). Vagus nerve stimulation therapy associated with weight loss increases energy expenditure, which is associated with increased BAT glucose uptake (179). Ephedrine-stimulated BAT metabolic activity is blunted in obesity (180). However, other studies have found that Isoprenaline and ephedrine did not activate BAT metabolic activity despite increasing whole body energy expenditure in lean men $(181,182)$. Significant BAT contribution to energy expenditure is nevertheless supported by the $\beta 3$ adrenergic agonist mirabegron-mediated increase in energy expenditure $(+203 \pm 40 \mathrm{kcal} /$ day $)$, associated with an increase in ${ }^{18}$ FDG BAT activity (183). However, this treatment is also associated with increased pulse rate and blood pressure, suggesting increased energy expenditure from the cardiovascular system.

Hypothyroidism and hyperthyroidism are conditions that reduce and increase, respectively, whole body energy expenditure. Although one study reported increased BAT glucose uptake with hyperthyroidism (184), others have reported no change in spontaneously occurring (185) or cold-induced BAT metabolic activity (186). Likewise, BAT activation has been observed with cancer cachexia $(187,188)$. Higher ${ }^{18}$ FDG BAT volume predicts less adipose tissue accumulation during cancer treatment in children (189). Association was also observed 
between reduction of BAT glucose uptake and chemotherapyinduced weight gain in women treated for breast cancer (190).

Some role for BAT in diet-induced thermogenesis has been proposed on the basis of preclinical studies (191). Postprandial increase in energy expenditure was reported to be higher in ${ }^{18}$ FDG BAT positive vs. BAT negative individuals, with lower respiratory quotient, but without significant change in total $24 \mathrm{~h}$ energy expenditure (192). BAT glucose uptake increases after meal intake, but is not related to diet-induced thermogenesis (193). Overfeeding, which increases energy expenditure (194), does not activate BAT glucose uptake (195). We showed no change in postprandial BAT dietary fatty acid and glucose uptake during cold exposure prior to vs. after cold acclimation for 4 weeks that activated BAT thermogenic activity 2 to 3 -fold (115). This suggests that cold-induced BAT activation does not change organ-specific postprandial glucose or dietary fatty acid partitioning between organs. Interestingly, our study showed a non-statistically significant trend toward greater cold-induced increase in BAT radio-density postprandially after cold acclimation (115). A very recent study from the Turku group (196) demonstrated meal-induced BAT oxygen consumption equivalent to that observed with mild cold stimulation, together with significant reduction of BAT NEFA uptake and a trend toward higher BAT radio-density. Again, this suggests a more important role for intracellular TG vs. circulating substrates to fuel BAT thermogenesis in humans. The study of $U$ Din et al. (196) estimated at $\sim 13$ kcal per day this meal-induced BAT contribution to energy expenditure. However, this calculation extrapolated BAT thermogenesis measured within the first postprandial hour to the entire day, which likely overestimates the contribution of this postprandial BAT thermogenesis to energy expenditure. Animal studies have consistently shown a decrease in classical BAT thermogenesis associated with a decrease in norepinephrine turnover with prolonged fasting (197). To our knowledge, there is no data available on the effect of prolonged or intermittent fasting on BAT activity or thermogenesis in humans.

The fact that BAT significantly takes up glucose, fatty acids, or other energy substrates from the circulation, and that it rapidly mobilizes its own TG content upon cold exposure does not prove that BAT contributes to thermogenesis and, therefore, to energy expenditure. Although direct BAT heat production was suggested by infrared spectroscopy [see (99) for review], this method cannot ascertain that heat difference measured on the surface of the skin overlying supraclavicular BAT is indeed produced by this organ. Likewise, measurement of BAT blood flow is an indirect measure of BAT thermogenesis and was shown in some instances to be dissociated from BAT thermogenesis (39). Supraclavicular BAT biopsies have been used to show higher ex vivo thermogenic activity in BAT vs. subcutaneous fat $(134,198)$. These biopsy methods are however incapable of measuring the true in vivo contribution of BAT to thermogenesis.

We used ${ }^{11} \mathrm{C}$-acetate, a tracer that allows quantification of Krebs' cycle rate through measure of ${ }^{11} \mathrm{CO}_{2}$ BAT production with dynamic PET acquisition to demonstrate more direct evidence of BAT's contribution to cold-induced thermogenesis in humans (108). In the latter study, we found that coldinduced increase in tissue thermogenesis was observed in BAT, but not in neck WAT or skeletal muscles. Using this tracer, we found that BAT thermogenesis can be increased by 2 to 3 fold by acclimation to cold $(73,115)$, that it is not reduced in $\mathrm{T} 2 \mathrm{D}$ vs. healthy individuals despite major reduction in BAT glucose uptake (109), and that it is blunted by inhibition of intracellular TG lipolysis with nicotinic acid (39). However, this method does not directly quantify BAT thermogenesis as ${ }^{11} \mathrm{CO}_{2}$ tissue production is only a surrogate of tissue oxygen consumption.

Direct measurement of BAT oxygen consumption has been performed by the groups of Otto Muzik $(199,200)$ and that of the Turku PET Centre (143) using ${ }^{15} \mathrm{O}_{2}$ dynamic PET acquisition. Using this method during very mild, short-term [60 min), but poorly controlled cold exposure, Muzik et al. estimated BAT thermogenesis to range between 15 to $25 \mathrm{kcal} /$ day (200). The Turku group reported BAT thermogenesis figures in the range of $\sim 7 \mathrm{kcal} /$ day at room temperature to $\sim 10$ $\mathrm{kcal} /$ day during mild cold exposure in healthy subjects (143). Although BAT oxygen consumption per gram of tissue is 2 to 10-fold higher than that observed in WAT and skeletal muscles at room temperature or during mild cold exposure (143), the small BAT total tissue mass makes its relative contribution to basal and cold-induced thermogenesis very small. However, the small BAT total mass was again determined using ${ }^{18}$ FDG PET, which may lead to underestimation of the contribution of BAT to thermogenesis. Unfortunately, the current PET scanners with a limited field of view ranging from 16 to $24 \mathrm{~cm}$ in most instances do not allow total body dynamic acquisition during ${ }^{15} \mathrm{O}_{2}$ or ${ }^{11} \mathrm{C}$-acetate administration. It is therefore not possible to simultaneously measure oxidative metabolism in all organs and all adipose tissue depots of the body. Furthermore, the very rapid tissue metabolism of these tracers makes impossible sequential dynamic acquisitions in different regions from the same tracer administration and safety considerations limit the number of sequential PET tracer administrations that can be made as part of experimental studies in humans. Therefore, the currently available methods cannot accurately determine total BAT contribution to thermogenesis.

Recently, radiological 3D mapping of possibly metabolically active adipose tissues has suggested a much greater metabolic potential for BAT (61). Using measures of total BAT volume from the later study (ranging from 510 to $2358 \mathrm{ml}$ ) (61) with the data on BAT oxidative metabolism per gram of tissue measured by U Din et al. (143) $\left[0.007 \mathrm{ml} . \mathrm{g}^{-1} \cdot \mathrm{min}^{-1}\right.$ at room temperature and $0.012 \mathrm{ml} \cdot \mathrm{g}^{-1} \cdot \mathrm{min}^{-1}$ during cold exposure), and assuming energy expenditure of $4.801 \mathrm{kcal}$ per liter of oxygen consumed (201) and an adipose tissue density of $0.925 \mathrm{~g} \cdot \mathrm{ml}^{-1}$ (202), BAT contribution to thermogenesis could range from $27-123 \mathrm{kcal}$ per day at room temperature to 46-211 kcal per day during mild cold exposure (Figure 8). Accurate determination of oxidative metabolism over total body BAT volume will be critical to quantify the true potential of BAT in energy expenditure in humans. 


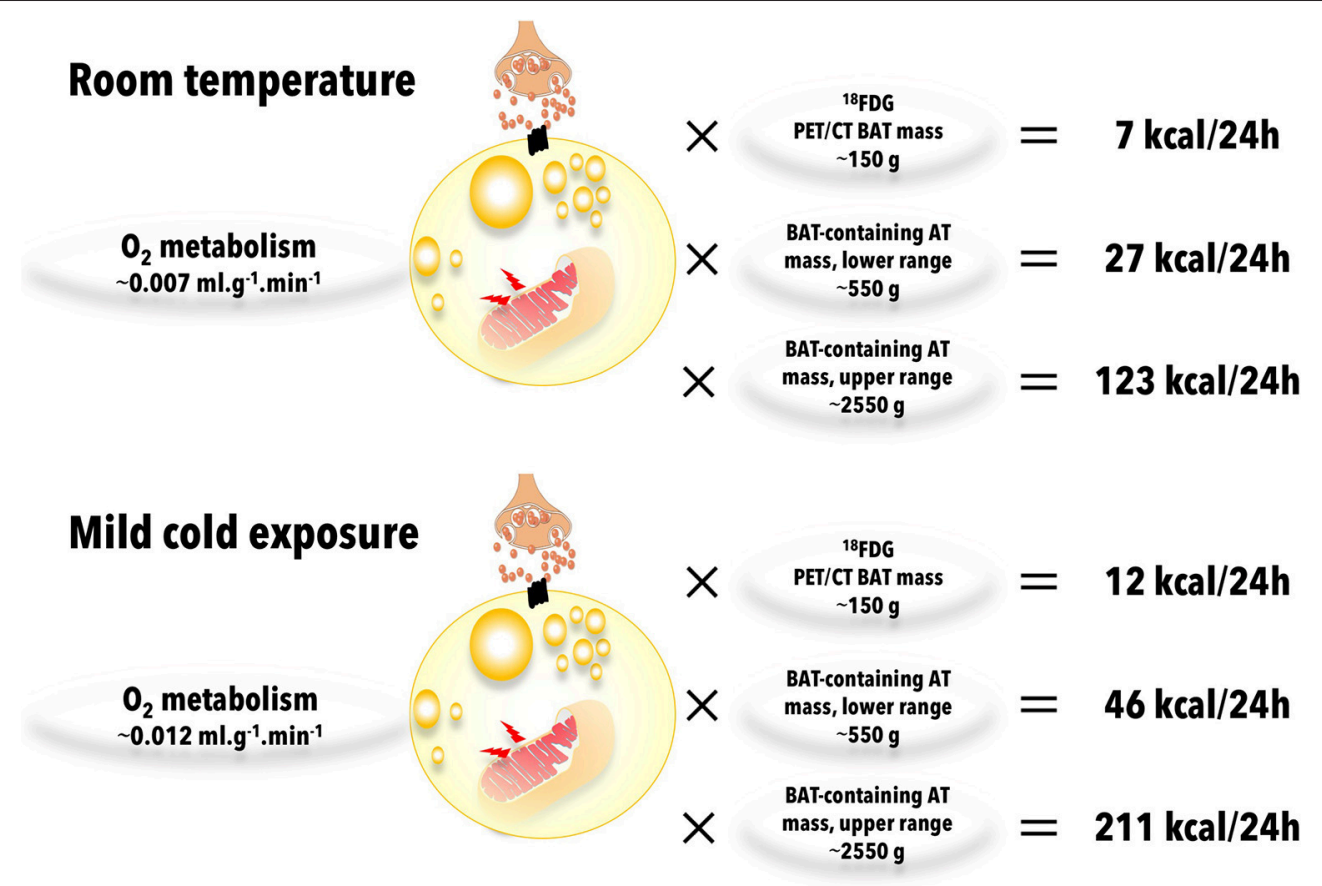

FIGURE 8 | Brown adipose tissue (BAT) oxidative metabolism and contribution to total body energy expenditure. Brown adipose tissue oxygen consumptions are from $U$ Din et al. (143) and brown adipose tissue-containing adipose tissue (AT) mass range is from Leitner et al. (61). Calculations were made assuming energy expenditure of $4.801 \mathrm{kcal}$ per liter of oxygen consumed (201) and an adipose tissue density of $0.925 \mathrm{~g} \cdot \mathrm{ml}^{-1}$ (202). AT, adipose tissue.

\section{IS THERE A CONTRIBUTION OF WAT BROWNING TO THERMOGENESIS AND ENERGY EXPENDITURE?}

In addition to the "classical" BAT depots, WAT "browning" (or "beiging") may also contribute to thermogenesis, although this is still hotly debated $(11,203-206)$. A detailed discussion on the mechanisms and cellular adaptations of WAT "browning" is beyond the scope of this review and has been the subject of excellent recent papers $(17,207,208)$. "Beige" cells express functional UCP1 and their development appears to be Prdm16dependent, as classical BAT adipocytes $(26,44,209)$. In rodents, chronic cold exposure, treatment with $\beta_{3}$-adrenergic or PPAR $\gamma$ agonists, and exercise $(38,209-213)$ were shown to induce "browning" of WAT preferentially in subcutaneous depots, while reduced "browning" is seen with aging (214).

Although more controversial, there is also some evidence for physiologically significant WAT "browning" in humans. Ageing is associated with reduced white adipose tissue "browning" $(169,215,216)$. Perirenal fat in women expresses UCP1 after exposure to cold environment, but difference in UCP1 expression does not translate into change in adipocyte respiration rate (217). Visceral fat "browning" per ${ }^{18}$ FDG PET/CT and histopathological examination has been shown in patients with pheochromocytoma or paraganglioma, associated with increased energy expenditure and diabetes $(61,218)$. Visceral fat glucose uptake was reduced by alpha blockade and removal of the tumor, associated with weight gain and reversal of diabetes. Cold acclimation however does not lead to "browning" of abdominal subcutaneous WAT in humans (71).

Seeing WAT "browning" using molecular markers, histological examination or even with ${ }^{18}$ FDG PET does not necessarily imply significant contribution to thermogenesis and energy expenditure. For example, PPAR $\gamma$ agonist treatment in rodents, while inducing WAT "browning" and BAT volume expansion, induces a reduction in sympathetic tone and thermogenesis (219-221). Recently, treatment with thiazolidinedione was shown to increase "browning" of subcutaneous WAT while reducing classical BAT glucose uptake and promoting weight gain in vivo in humans (222). We have shown in rats that chronic cold exposure or beta-3 adrenergic agonist treatment, while leading to robust "browning" of WAT as assessed by histological examination, UCP1 gene and protein expression, and mitochondrial DNA content, do not lead to significant increase in WAT thermogenic activity as assessed by ${ }^{11} \mathrm{C}$-acetate PET (213). This lack of WAT thermogenic activation contrasted with a very robust thermogenic activation of classical BAT simultaneously assessed by ${ }^{11} \mathrm{C}$-acetate PET in the same animals. It is also important to note that despite significant WAT "browning," WAT UCP1 expression and mitochondrial DNA content remain one to two orders of magnitude below that observed in classical BAT $(213,223,224)$. The total volume of WAT "browning" as well as its thermogenic activity have yet to be measured in humans. Based on the data available, it cannot be concluded at the moment that WAT "browning" plays 
a significant role in energy expenditure through mitochondrial uncoupling to similar extent as in "classical BAT" depots.

WAT "browning" can nevertheless potentially contribute to energy expenditure through activation of futile metabolic cycles. These cycles include TG lipolysis/esterification, activation of $\mathrm{Na}^{+}-\mathrm{K}^{+}$-ATPase, creatine/phosphocreatine cycling, and ATPdependent $\mathrm{Ca}^{2+}$ cycling $(206,225,226)$. For example, in the absence of UCP1, energy-consuming and heat-producing WAT metabolic adaptations nevertheless occur, including smaller multilocular lipid droplets, larger mitochondrial content, and increased sarcoendoplasmic reticulum $\mathrm{Ca}^{2+}$-ATPase expression (227). These adaptations are also associated with enhanced capacity of WAT to oxidize fatty acids (227), an outcome that can also be obtained using energy restriction or omega-3 supplementation (228). The group of Shingo Kajimura recently demonstrated UCP1-independent increased beige fat ex vivo glucose uptake, oxidation and thermogenesis mediated through enhanced ATP-dependent $\mathrm{Ca}^{2+}$ cycling from sarco/endoplasmic reticulum $\mathrm{Ca}^{2+}$-ATPase $2 \mathrm{~b}$ and ryanodine receptor 2 (226). UCP1-independent BAT and beige fat thermogenesis from creatine/phosphocreatine cycling has also been demonstrated in vitro in human and murine cells and in vivo in mice (225).

During cold exposure, there is substantial activation of intracellular TG lipolysis in BAT and in WAT (see sections on Circulating fatty acids and Intracellular triglycerides above). Major stimulation of TG/fatty acid cycling is therefore expected to occur in both tissues, especially in BAT where glycerol can be utilized directly to a greater extent (116), and where glyceroneogenesis (123) and glycolysis (see section Glucose) occur at much faster rates. Of course, intracellular reesterification of fatty acids is fueled by Krebs' cycle and is accounted for when BAT oxidative metabolism is measured by the ${ }^{15} \mathrm{O}_{2}$ or ${ }^{11} \mathrm{C}$-acetate PET methods. Nevertheless, part of the fatty acids produced by intracellular lipolysis in BAT could potentially be reesterified in other organs, leading to some additional energy expenditure. The extent of adipose tissue metabolic adaptation to prolonged cold exposure or pharmacological activation of BAT thermogenesis has not been determined thus far. However, adaptation of WAT TG/fatty acid cycling can reach impressive levels in humans. For example, using stable isotope tracer methodology in morbidly obese subjects before and 3 days, 3 months and 1 year after they underwent bariatric surgery, we showed that WAT NEFA production rate and storage capacity can be sustained at the same level despite a more than 3-fold reduction in adipose tissue mass (229), likely resulting in much enhanced energy expenditure per adipose tissue mass. Whether such WAT adaptations may contribute to chronic shift of total body energy balance remains to be tested.

\section{CLINICAL IMPLICATIONS OF BAT THERMOGENESIS AND ENERGY SUBSTRATE UTILIZATION}

The obesity epidemic is mainly driven by a chronic positive energy balance-a difference of $<0.1 \%$ between daily intake and expenditure-that is sustained over years. The average weight gain which when sustained over young adulthood leads to obesity by middle age is an incremental $\sim 0.5-0.7 \mathrm{~kg}$ per year $(230,231)$. On a daily basis, this is an energy surplus of a mere $\sim 12-17 \mathrm{kcal}$ i.e., less than a $5 \mathrm{~g}$ cube of sugar, for an average energy density of $8840 \mathrm{kcal} / \mathrm{kg}$ of body (232). It is common among people who lose weight, to experience a drop in total energy expenditureon average, $\sim 25 \mathrm{kcal} /$ day per $\mathrm{kg}$ of weight loss (232). This phenomenon, however, frustrates attempts by most people to maintain healthy weight. The inter-individual variability of this drop in energy expenditure can also significantly influence the rate of diet-induced weight loss $(232,233)$. When greater weight loss is maintained over time, the health advantages of lifestyleand/or bariatric surgery-induced weight loss tend to be more significant (234-236). However, when as little as a $\sim 2$-kg weight loss is maintained over a span of 10 years-i.e., an average negative balance of $\sim 48 \mathrm{kcal}$ per day-the incidence of T2D is curbed by as much as $18-34 \%$ (237). Therefore, small shifts in energy balance that are sustained over time can exert major effects on health outcomes.

As discussed above, current estimates of BAT contribution to energy expenditure in humans are in the range of $\sim 7-25 \mathrm{kcal}$ per day based on ${ }^{15} \mathrm{O}_{2}$ PET data recorded at room temperature or during mild acute cold exposure. Although small, these figures may be underestimated because of the current limitations of ${ }^{18}$ FDG PET to measure total BAT volume, especially in obese and T2D individuals. Whether enhanced TG/fatty acid recycling could add to BAT (or "beige" adipose tissue) thermogenesis has not been quantified in humans. It is also clear that BAT thermogenesis can be recruited to a significant extent with cold acclimation (73) and that its absence or stimulation lead to changes in cold-induced muscle shivering and non-shivering thermogenesis $(39,113)$. Activation of BAT thermogenesis may therefore be useful for people with occupational cold exposure. Attempts to activate BAT using cold over a prolonged period of time in humans did not result in weight loss in most $(73,74,104$, $105,176)$ but not all studies (72), likely because of compensatory increase in energy intake. Circulating endocannabinoids increase with cold exposure (238), suggesting a possible mechanism for cold-induced increase in energy intake. It is also important to note that obese individuals need to reach lower skin temperature to induce cold-induced thermogenesis, due to increased body heat generation (i.e., increased resting energy expenditure driven by larger lean mass), not the generally falsely assumed increased fat layer insulation (239). The well-documented beneficial effect of chronic cold exposure on total body insulin sensitivity (74, $104,105,176)$ is driven by muscle, not BAT thermogenic activity (107). Therefore, cold-induced activation of BAT thermogenesis cannot by itself be proposed to shift caloric balance in humans. However, the possibility that it may serve as an adjunct preventive or therapeutic avenue to lifestyle interventions and/or appetitesuppressant drugs for obesity begs further investigations.

Rodent studies have suggested that BAT and/or WAT "browning" may be implicated in some of the beneficial metabolic effects of physical exercise [see (208, 240-242) for recent reviews on this topic]. At least four mechanisms have been evoked to drive such effects. First, physical exercise is associated with increased adrenergic stimulation, which may lead to direct 
activation of BAT thermogenesis and WAT "browning." Second, exercise induces secretion of myokines such as irisin or meteorin like, cardiac natriuretic peptides, and fibroblast growth factor 21, that have all been implicated in BAT metabolic activity (243-245). Third, BAT-derived circulating factor such as IL-6 (246) or the recently discovered 12,13 diHOME (247) have been implicated in systemic metabolic improvement in mice. Fourth, exercise may lead to improved leptin and insulin signaling in the brain, with enhanced pro-opio-melanocortin neurons activation leading to WAT browning (241). However, exercise has long been shown to reduce cold-induced thermogenesis and cold acclimation in rats $(248,249)$, likely because heat produced by exercise downregulates the sympathetic stimulatory output signal to BAT. As mentioned above, athletes have lower BAT volume and activity based on ${ }^{18} \mathrm{FDG}$ PET/CT $(172,173)$ and BAT glucose uptake is reduced following short-term exercise training in healthy men (130). Different exercise duration, intensity and type can result in different adrenergic and systemic stress responses. Furthermore, as discussed above, BAT glucose uptake cannot be taken as a reliable index of BAT thermogenesis. To our knowledge, there is no study published in humans that has measured BAT thermogenesis per se in response to exercise. It is therefore difficult to draw definitive conclusions on the effect of exercise on BAT thermogenic activity in humans given the data currently available.

From epidemiological (retrospective) studies that have been published, there seems to be a graded South-to-North incremental prevalence of spontaneously active BAT. For example, the reported prevalence in Boston (latitude: $42^{\circ} 21^{\prime} 30^{\prime \prime}$ North) is $4 \%$ (54) whereas it is $6.8 \%$ in Sherbrooke (latitude: $45^{\circ} 24^{\prime} 30^{\prime \prime}$ North) (60). As it has been discussed above, cold acclimation leads to clear increase in BAT thermogenic activity and capacity in humans (73) and, therefore, cold exposure is an important driver of this South-to-North incremental prevalence of metabolically active BAT. Whether ethnic background differences may explain changes in BAT metabolic activity is more controversial. For example, direct comparison between subjects of South Asian vs. Europid descent showed either no change in BAT ${ }^{18} \mathrm{FDG}$ uptake (250), or reduced BAT ${ }^{18} \mathrm{FDG}$ volume (but not activity) (170). In the latter study, all participants were Dutch (therefore living at the same latitude) and participants from South Asian descent also displayed lower resting energy expenditure and lower coldinduced non-shivering thermogenesis. The same research group later demonstrated that this blunted thermogenic response in subjects from South Asian descent may be due to increased endocannabinoid tone (238). From the limited data available, we can conclude that cold exposure is clearly linked to differences of BAT activity between different populations, and that genetic/ethnic background differences may also play a role in modulating BAT metabolic responses. More data are needed to address this issue.

Despite encouraging results of BAT metabolic activation with a single-dose administration of mirabegron, a beta- 3 adrenergic agonist (183), this class of agents has proven ineffective for the treatment of obesity or T2D in early clinical trials (251, 252). Furthermore, cardiovascular safety is of concern given the increase in heart rate and blood pressure observed with this class of medication, likely mediated through beta- 1 and/or beta- 2 spillover effects. Capsinoids, catechins and caffeine activate BAT glucose uptake and whole body energy expenditure $(177,178)$, but with variable results on clinical outcomes (253-256). The effect of beta- 3 adrenergic agonists, capsinoids, and catechins on BAT thermogenesis however remains to be determined in humans. The intriguing possibility that BAT thermogenesis could be used as a personalized medicine approach to guide the use of these agents for the prevention or treatment of obesity also remains unexplored.

\section{CONCLUSION}

BAT is a fascinating organ that possesses a very large thermogenic potential per mass of tissue. This tissue has an astounding capacity to rapidly mobilize its own TG content upon cold exposure. Fatty acids from this intense intracellular lipolysis are likely the main substrates for BAT thermogenesis, although the metabolic fate of fatty acids in BAT in vivo in humans has not yet been reported. The contribution of BAT and "beige" adipose tissue to thermogenesis through accelerated TG/fatty acid cycling also need to be quantified. BAT is of clear physiological relevance for cold-induced thermogenesis and is integral to a multisystem adaptive response to cold. The current estimated contribution of BAT to energy expenditure is however low due to its small volume measured using ${ }^{18} \mathrm{FDG}$ PET. The latter method has major limitations for accurate measurement of BAT volume, likely leading to underestimation of the true contribution of this tissue to thermogenesis, especially in individuals with obesity and T2D. The current estimates of BAT thermogenesis are at the lower end of energy expenditure shifts that could lead to clinical benefits if sustained without off-target side-effects over the long term. Currently estimated plasma glucose, NEFA or lipoprotein utilization by BAT is also too low to be deemed of clinical relevance to treat T2D or lipid disorders. The development of novel imaging methods for accurate quantification of BAT volume is however required to delineate the true potential of targeting BAT thermogenesis to prevent and/or treat cardiometabolic disorders. With the demonstration of a slightly higher contribution to thermogenesis, it is still possible that metabolic activation of BAT could serve as an effective adjunct therapeutic target to existing treatments for obesity and T2D. Whether monitoring of the effect of clinical interventions on BAT thermogenesis may help personalize treatment selection for obesity and/or T2D also needs to be addressed in future studies.

\section{AUTHOR CONTRIBUTIONS}

AC wrote the first draft of the manuscript and drafted all figures, except Figure 4. DB critically reviewed the manuscript, drafted Figure 4, and contributed to draft Figures 3, 7. KV, DR, FH, and ÉT critically reviewed the manuscript and contributed to draft Figure 2. 


\section{ACKNOWLEDGMENTS}

AC holds the GSK Chair in Diabetes of Université de Sherbrooke. Original work from our group in the field of human brown adipose tissue metabolism has been funded by grants from

\section{REFERENCES}

1. GBD 2015 Obesity Collaborators, Afshin A, Forouzanfar MH, Reitsma MB, Sur P, Estep K, et al. Health effects of overweight and obesity in 195 Countries over 25 years. N Engl J Med (2017) 377:13-27. doi: 10.1056/NEJMoa1614362

2. Plourde CE, Grenier-Larouche T, Caron-Dorval D, Biron S, Marceau S, Lebel S, et al. Biliopancreatic diversion with duodenal switch improves insulin sensitivity and secretion through caloric restriction. Obesity (2014) 22:1838-46. doi: 10.1002/oby.20771

3. Grenier-Larouche T, Carreau AM, Carpentier AC. Early metabolic improvement after bariatric surgery: the first steps toward remission of type 2 diabetes. Can J Diabetes (2017) 41:418-25. doi: 10.1016/j.jcjd.2016.10.013

4. Lean ME, Leslie WS, Barnes AC, Brosnahan N, Thom G, Mccombie L, et al. Primary care-led weight management for remission of type 2 diabetes (DiRECT): an open-label, cluster-randomised trial. Lancet (2017) 391:513-630. doi: 10.1016/S0140-6736(17)33102-1

5. Narayanaswami V, Dwoskin LP. Obesity: current and potential pharmacotherapeutics and targets. Pharmacol Ther. (2017) 170:116-47. doi: 10.1016/j.pharmthera.2016.10.015

6. Khera R, Murad MH, Chandar AK, Dulai PS, Wang Z, Prokop LJ, et al. Association of pharmacological treatments for obesity with weight loss and adverse events: a systematic review and meta-analysis. JAMA (2016) 315:2424-34. doi: 10.1001/jama.2016.7602

7. Foster DO, Frydman ML. Tissue distribution of cold-induced thermogenesis in conscious warm- or cold-acclimated rats reevaluated from changes in tissue blood flow: the dominant role of brown adipose tissue in the replacement of shivering by nonshivering thermogenesis. Can J Physiol Pharmacol. (1979) 57:257-70. doi: 10.1139/y79-039

8. Heldmaier G, Buchberger A. Sources of heat during nonshivering thermogenesis in Djungarian hamsters: a dominant role of brown adipose tissue during cold adaptation. J Comp Physiol B (1985) 156:237-45. doi: 10.1007/BF00695778

9. Himms-Hagen J. Brown adipose tissue thermogenesis: interdisciplinary studies. FASEB J. (1990) 4:2890-8. doi: 10.1096/fasebj.4.11.2199286

10. Klingenspor $M$. Cold-induced recruitment of brown adipose tissue thermogenesis. Exp Physiol. (2003) 88:141-8. doi: 10.1113/eph8802508

11. Blondin DP, Carpentier AC. The role of BAT in cardiometabolic disorders and aging. Best Pract Res Clin Endocrinol Metab. (2016) 30:497-513. doi: 10.1016/j.beem.2016.09.002

12. Schlein C, Heeren J. Implications of thermogenic adipose tissues for metabolic health. Best Pract Res Clin Endocrinol Metab. (2016) 30:487-96. doi: 10.1016/j.beem.2016.08.002

13. Schrauwen $P$, Van Marken Lichtenbelt WD. Combatting type 2 diabetes by turning up the heat. Diabetologia (2016) 59:2269-79. doi: 10.1007/s00125-016-4068-3

14. Virtanen KA. The rediscovery of BAT in adult humans using imaging. Best Pract Res Clin Endocrinol Metab. (2016) 30:471-7. doi: 10.1016/j.beem.2016.09.001

15. Scheele C, Nielsen S. Metabolic regulation and the anti-obesity perspectives of human brown fat. Redox Biol. (2017) 12:770-5. doi: 10.1016/j.redox.2017.04.011

16. Wolf Y, Boura-Halfon S, Cortese N, Haimon Z, Sar Shalom H, Kuperman $\mathrm{Y}$, et al. Brown-adipose-tissue macrophages control tissue innervation and homeostatic energy expenditure. Nat Immunol. (2017) 18:665-74. doi: 10.1038/ni.3746

17. Villarroya F, Cereijo R, Villarroya J, Gavalda-Navarro A, Giralt M. Toward an understanding of how immune cells control brown and beige adipobiology. Cell Metab. (2018) 27:954-61. doi: 10.1016/j.cmet.2018.04.006 the Canadian Diabetes Association, the Canadian Institutes of Health Research (Grant no. 299962) and the Natural Sciences and Engineering Research Council of Canada. KV received financial support from Academy of Finland (259926). We thank Ms. Anick Turgeon for drafting the illustrations of Figures 1-8.

18. Bolus WR, Hasty AH. Contributions of innate type 2 inflammation to adipose function. J Lipid Res. (2018). doi: 10.1194/jlr.R085993

19. Cannon B, Nedergaard J. Brown adipose tissue: function and physiological significance. Physiol Rev. (2004) 84:277-359. doi: 10.1152/physrev.00015.2003

20. Aherne W, Hull D. Brown adipose tissue and heat production in the newborn infant. J PatholBacteriol. (1966) 91:223-34. doi: 10.1002/path.1700910126

21. $\mathrm{Hu} \mathrm{HH}$, Tovar JP, Pavlova Z, Smith ML, Gilsanz V. Unequivocal identification of brown adipose tissue in a human infant. J Magn Reson Imaging (2012) 35:938-42. doi: 10.1002/jmri.23531

22. Lidell ME, Betz MJ, Dahlqvist Leinhard O, Heglind M, Elander L, Slawik M, et al. Evidence for two types of brown adipose tissue in humans. Nat Med. (2013) 19:631-4. doi: 10.1038/nm.3017

23. Drubach LA, Palmer EL, Connolly LP, Baker A, Zurakowski D, et al. Pediatric brown adipose tissue: detection, epidemiology, and differences from adults. J Pediatr. (2011) 159:939-44. doi: 10.1016/j.jpeds.2011. 06.028

24. Gilsanz V, Smith ML, Goodarzian F, Kim M, Wren TA, Hu HH. Changes in brown adipose tissue in boys and girls during childhood and puberty. J Pediatr. (2012) 160:604-9.e601. doi: 10.1016/j.jpeds.2011. 09.035

25. Cinti S. The adipose organ: morphological perspectives of adipose tissues. Proc Nutr Soc. (2001) 60:319-28. doi: 10.1079/PNS200192

26. Smorlesi A, Frontini A, Giordano A, Cinti S. The adipose organ: whitebrown adipocyte plasticity and metabolic inflammation. Obes Rev. (2012) 13(Suppl. 2):83-96. doi: 10.1111/j.1467-789X.2012.01039.x

27. Ricquier D. Respiration uncoupling and metabolism in the control of energy expenditure. Proc Nutr Soc. (2005) 64:47-52. doi: 10.1079/PNS2004408

28. Nicholls DG, Locke RM. Thermogenic mechanisms in brown fat. Physiol Rev. (1984) 64:1-64. doi: 10.1152/physrev.1984.64.1.1

29. Mozo J, Emre Y, Bouillaud F, Ricquier D, Criscuolo F. Thermoregulation: what role for UCPs in mammals and birds? Bio sci Rep. (2005) 25:227-49. doi: 10.1007/s10540-005-2887-4

30. Garlid KD, Jaburek M, Jezek P. The mechanism of proton transport mediated by mitochondrial uncoupling proteins. FEBS Lett. (1998) 438:10-4. doi: 10.1016/S0014-5793(98)01246-0

31. Klingenberg $M$, Echtay KS. Uncoupling proteins: the issues from a biochemist point of view. Biochim Biophys Acta (2001) 1504:128-43. doi: 10.1016/S0005-2728(00)00242-5

32. Gonzalez-Barosso MMRE. The role of fatty acids in the activity of the uncoupling protein. Curr Chem Biol (2009) 3:180-8. doi: 10.1079/PNS2003336

33. Fedorenko A, Lishko PV, Kirichok Y. Mechanism of fatty-acid-dependent UCP1 uncoupling in brown fat mitochondria. Cell (2012) 151:400-13. doi: 10.1016/j.cell.2012.09.010

34. Bachman ES, Dhillon H, Zhang CY, Cinti S, Bianco AC, Kobilka BK, et al. betaAR signaling required for diet-induced thermogenesis and obesity resistance. Science (2002) 297:843-5. doi: 10.1126/science.1073160

35. Jimenez M, Leger B, Canola K, Lehr L, Arboit P, Seydoux J, et al. $\operatorname{Beta}(1) /$ beta(2)/beta(3)-adrenoceptor knockout mice are obese and coldsensitive but have normal lipolytic responses to fasting. FEBS Lett. (2002) 530:37-40. doi: 10.1016/S0014-5793(02)03387-2

36. Lowell BB, Bachman ES. Beta-Adrenergic receptors, diet-induced thermogenesis, and obesity. J Biol Chem. (2003) 278:29385-8. doi: 10.1074/jbc.R300011200

37. Collins S, Cao W, Robidoux J. Learning new tricks from old dogs: beta-adrenergic receptors teach new lessons on firing up adipose tissue metabolism. Mol Endocrinol. (2004) 18:2123-31. doi: 10.1210/me.2004-0193 
38. Labbe SM, Caron A, Bakan I, Laplante M, Carpentier AC, Lecomte R, et al. in vivo measurement of energy substrate contribution to coldinduced brown adipose tissue thermogenesis. FASEB J (2015) 29:2046-58. doi: 10.1096/fj.14-266247

39. Blondin DP, Frisch F, Phoenix S, Guerin B, Turcotte EE, Haman F, et al. Inhibition of intracellular triglyceride lipolysis suppresses cold-induced brown adipose tissue metabolism and increases shivering in humans. Cell Metab. (2017) 25:438-47. doi: 10.1016/j.cmet.2016.12.005

40. Schreiber R, Diwoky C, Schoiswohl G, Feiler U, Wongsiriroj N, Abdellatif $\mathrm{M}$, et al. Cold-induced thermogenesis depends on ATGL-mediated lipolysis in cardiac muscle, but not brown adipose tissue. Cell Metab. (2017) 26:75363.e757. doi: 10.1016/j.cmet.2017.09.004

41. Shin H, Ma Y, Chanturiya T, Cao Q, Wang Y, Kadegowda AKG, et al. Lipolysis in brown adipocytes is not essential for coldinduced thermogenesis in mice. Cell Metab (2017) 26:764-77.e765. doi: 10.1016/j.cmet.2017.09.002

42. Seale P, Bjork B, Yang W, Kajimura S, Chin S, Kuang S, et al. PRDM16 controls a brown fat/skeletal muscle switch. Nature (2008) 454:961-7. doi: $10.1038 /$ nature07182

43. Seale P, Kajimura S, Spiegelman BM. Transcriptional control of brown adipocyte development and physiological function-of mice and men. Genes Dev. (2009) 23:788-97. doi: 10.1101/gad.1779209

44. Kajimura S, Seale P, Spiegelman BM. Transcriptional control of brown fat development. Cell Metab. (2010) 11:257-62. doi: 10.1016/j.cmet.2010.03.005

45. Walden TB, Hansen IR, Timmons JA, Cannon B, Nedergaard J. Recruited vs. nonrecruited molecular signatures of brown, "brite," and white adipose tissues. Am J Physiol Endocrinol Metab. (2012) 302:E19-31. doi: 10.1152/ajpendo.00249.2011

46. Wu J, Bostrom P, Sparks LM, Ye L, Choi JH, Giang AH, et al. Beige adipocytes are a distinct type of thermogenic fat cell in mouse and human. Cell (2012) 150:366-76. doi: 10.1016/j.cell.2012.05.016

47. Porter C, Herndon DN, Chondronikola M, Chao T, Annamalai P, Bhattarai $\mathrm{N}$, et al. Human and mouse brown adipose tissue mitochondria have comparable UCP1 function. Cell Metab. (2016) 24:246-55. doi: 10.1016/j.cmet.2016.07.004

48. Ingram JR, Dougan M, Rashidian M, Knoll M, Keliher EJ, Garrett S, et al. PDL1 is an activation-independent marker of brown adipocytes. Nat Commun. (2017) 8:647. doi: 10.1038/s41467-017-00799-8

49. Hull D. The structure and function of brown adipose tissue. Br Med Bull. (1966) 22:92-6. doi: 10.1093/oxfordjournals.bmb.a070447

50. Heaton JM. The distribution of brown adipose tissue in the human. J Anat. (1972) 112:35-9.

51. Huttunen P, Hirvonen J, Kinnula V. The occurrence of brown adipose tissue in outdoor workers. Eur J Appl Physiol Occup Physiol. (1981) 46:339-45. doi: $10.1007 / \mathrm{BF} 00422121$

52. Hany TF, Gharehpapagh E, Kamel EM, Buck A, Himms-Hagen J, Von Schulthess GK. Brown adipose tissue: a factor to consider in symmetrical tracer uptake in the neck and upper chest region. EurJ Nucl Med Mol Imaging (2002) 29:1393-8. doi: 10.1007/s00259-002-0902-6

53. Nedergaard J, Bengtsson T, Cannon B. Unexpected evidence for active brown adipose tissue in adult humans. AmJ Physiol Endocrinol Metab. (2007) 293:E444-52. doi: 10.1152/ajpendo.00691.2006

54. Cypess AM, Lehman S, Williams G, Tal I, Rodman D, Goldfine AB, et al. Identification and importance of brown adipose tissue in adult humans. $N$ Engl J Med. (2009) 360:1509-17. doi: 10.1056/NEJMoa0810780

55. Saito M, Okamatsu-Ogura Y, Matsushita M, Watanabe K, Yoneshiro T, NioKobayashi J, et al. High incidence of metabolically active brown adipose tissue in healthy adult humans: effects of cold exposure and adiposity. Diabetes (2009) 58:1526-31. doi: 10.2337/db09-0530

56. Van Marken Lichtenbelt WD, Vanhommerig JW, Smulders NM, Drossaerts JM, Kemerink GJ, Bouvy ND, et al. Cold-activated brown adipose tissue in healthy men. $N$ Engl J Med. (2009) 360:1500-8. doi: 10.1056/NEJMoa0808718

57. Virtanen KA, Lidell ME, Orava J, Heglind M, Westergren R, Niemi T, et al. Functional brown adipose tissue in healthy adults. N Engl J Med. (2009) 360:1518-25. doi: 10.1056/NEJMoa0808949

58. Chen KY, Cypess AM, Laughlin MR, Haft CR, Hu HH, Bredella MA, et al. Brown adipose reporting criteria in imaging studies (BARCIST 1.0): recommendations for standardized FDG-PET/CT experiments in humans. Cell Metab. (2016) 24:210-22. doi: 10.1016/j.cmet.2016.07.014

59. Blondin DP, Labbe SM, Turcotte EE, Haman F, Richard D, Carpentier AC. A critical appraisal of brown adipose tissue metabolism in humans. Clin Lipidol. (2015) 10:259-80. doi: 10.2217/clp.15.14

60. Ouellet V, Routhier-Labadie A, Bellemare W, Lakhal-Chaieb L, Turcotte E, Carpentier AC, et al. Outdoor temperature, age, sex, body mass index, and diabetic status determine the prevalence, mass, and glucose-uptake activity of 18F-FDG-detected BAT in humans. J Clin Endocrinol Metab. (2011) 96:192-9. doi: 10.1210/jc.2010-0989

61. Leitner BP, Huang S, Brychta RJ, Duckworth CJ, Baskin AS, Mcgehee S, et al. Mapping of human brown adipose tissue in lean and obese young men. Proc Natl Acad Sci USA. (2017) 114:8649-54. doi: 10.1073/pnas.1705287114

62. Schrauwen-Hinderling VB, Carpentier AC. Molecular imaging of postprandial metabolism. J Appl Physiol. (2018) 124:504-11. doi: 10.1152/japplphysiol.00212.2017

63. Parysow O, Mollerach AM, Jager V, Racioppi S, San Roman J, Gerbaudo VH. Low-dose oral propranolol could reduce brown adipose tissue F-18 FDG uptake in patients undergoing PET scans. Clin Nucl Med. (2007) 32:351-7. doi: 10.1097/01.rlu.0000259570.69163.04

64. Soderlund V, Larsson SA, Jacobsson H. Reduction of FDG uptake in brown adipose tissue in clinical patients by a single dose of propranolol. Eur J Nucl Med Mol Imaging (2007) 34:1018-22. doi: 10.1007/s00259-006-0318-9

65. Lee P, Greenfield JR, Ho KK, Fulham MJ. A critical appraisal of the prevalence and metabolic significance of brown adipose tissue in adult humans. Am J Physiol Endocrinol Metab. (2010) 299:E601-6. doi: 10.1152/ajpendo.00298.2010

66. Persichetti A, Sciuto R, Rea S, Basciani S, Lubrano C, Mariani S, et al. Prevalence, mass, and glucose-uptake activity of (1)(8)F-FDG-detected brown adipose tissue in humans living in a temperate zone of Italy. PLoS ONE (2013) 8:e63391. doi: 10.1371/journal.pone.0063391

67. Bahler L, Deelen JW, Hoekstra JB, Holleman F, Verberne HJ. Seasonal influence on stimulated BAT activity in prospective trials: a retrospective analysis of BAT visualized on 18F-FDG PET-CTs and 123I-mIBG SPECT-CTs. J Appl Physiol. (2016) 120:1418-23. doi: 10.1152/japplphysiol.00008.2016

68. Lee P, Bova R, Schofield L, Bryant W, Dieckmann W, Slattery A, et al. Brown adipose tissue exhibits a glucose-responsive thermogenic biorhythm in humans. Cell Metab. (2016) 23:602-9. doi: 10.1016/j.cmet.2016.02.007

69. Green AL, Bagci U, Hussein S, Kelly PV, Muzaffar R, NeuschwanderTetri BA, et al. Brown adipose tissue detected by PET/CT imaging is associated with less central obesity. Nucl Med Commun. (2017) 38:629-35. doi: 10.1097/MNM.0000000000000691

70. Steinberg JD, Vogel W, Vegt E. Factors influencing brown fat activation in FDG PET/CT: a retrospective analysis of 15,000+ cases. Br J Radiol. (2017) 90:20170093. doi: 10.1259/bjr.20170093

71. Van Der Lans AA, Hoeks J, Brans B, Vijgen GH, Visser MG, Vosselman MJ, et al. Cold acclimation recruits human brown fat and increases nonshivering thermogenesis. J Clin Invest. (2013) 123:3395-403. doi: 10.1172/JCI68993

72. Yoneshiro T, Aita S, Matsushita M, Kayahara T, Kameya T, Kawai Y, et al. Recruited brown adipose tissue as an antiobesity agent in humans. J Clin Invest. (2013) 123:3404-8. doi: 10.1172/JCI67803

73. Blondin DP, Labbe SM, Tingelstad HC, Noll C, Kunach M, Phoenix $\mathrm{S}$, et al. Increased brown adipose tissue oxidative capacity in coldacclimated humans. J Clin Endocrinol Metab. (2014) 99:E438-46. doi: 10.1210/jc.2013-3901

74. Hanssen MJ, Van Der Lans AA, Brans B, Hoeks J, Jardon KM, Schaart G, et al. Short-term cold acclimation recruits brown adipose tissue in obese humans. Diabetes (2016) 65:1179-89. doi: 10.2337/db15-1372

75. Eriksson O, Mikkola K, Espes D, Tuominen L, Virtanen K, Forsback $\mathrm{S}$, et al. The cannabinoid receptor- 1 is an imaging biomarker of brown adipose tissue. J Nucl Med. (2015) 56:1937-41. doi: 10.2967/jnumed.115.1 56422

76. Hwang JJ, Yeckel CW, Gallezot JD, Aguiar RB, Ersahin D, Gao H, et al. Imaging human brown adipose tissue under room temperature conditions with (11)C-MRB, a selective norepinephrine transporter PET ligand. Metabolism (2015) 64:747-55. doi: 10.1016/j.metabol.2015. 03.001 
77. Madar I, Naor E, Holt D, Ravert H, Dannals R, Wahl R. Brown adipose tissue response dynamics: in vivo insights with the voltage sensor $18 \mathrm{~F}$ fluorobenzyl triphenyl phosphonium. PLOS ONE (2015) 10:e0129627. doi: 10.1371/journal.pone.0129627

78. Muzik O, Mangner TJ, Leonard WR, Kumar A, Granneman JG. Sympathetic innervation of cold-activated brown and white fat in lean young adults. $J$ Nucl Med. (2017) 58:799-806. doi: 10.2967/jnumed.116.180992

79. Ran C, Albrecht DS, Bredella MA, Yang J, Yang J, Liang SH, et al. PET Imaging of Human Brown Adipose Tissue with the TSPO Tracer [(11)C]PBR28. Mol Imaging Biol. (2017) 20:188-93. doi: 10.1007/s11307-017-1129-z

80. Admiraal WM, Holleman F, Bahler L, Soeters MR, Hoekstra JB, Verberne HJ. Combining 123I-metaiodobenzylguanidine SPECT/CT and 18F-FDG PET/CT for the assessment of brown adipose tissue activity in humans during cold exposure. J Nucl Med. (2013) 54:208-12. doi: 10.2967/jnumed.112.111849

81. Holstila M, Virtanen KA, Gronroos TJ, Laine J, Lepomaki V, Saunavaara J, et al. Measurement of brown adipose tissue mass using a novel dualecho magnetic resonance imaging approach: a validation study. Metabolism (2013) 62:1189-98. doi: 10.1016/j.metabol.2013.03.002

82. Hu HH, Perkins TG, Chia JM, Gilsanz V. Characterization of human brown adipose tissue by chemical-shift water-fat MRI. AJR Am J Roentgenol. (2013) 200:177-83. doi: 10.2214/AJR.12.8996

83. Van Rooijen BD, Van Der Lans AA, Brans B, Wildberger JE, Mottaghy $\mathrm{FM}$, Schrauwen $\mathrm{P}$, et al. Imaging cold-activated brown adipose tissue using dynamic $\mathrm{T} 2$-weighted magnetic resonance imaging and 2-deoxy-2[18F]fluoro-D-glucose positron emission tomography. Invest Radiol. (2013) 48:708-14. doi: 10.1097/RLI.0b013e31829363b8

84. Crane JD, Mottillo EP, Farncombe TH, Morrison KM, Steinberg GR. A standardized infrared imaging technique that specifically detects UCP1-mediated thermogenesis in vivo. Mol Metab. (2014) 3:490-4. doi: 10.1016/j.molmet.2014.04.007

85. Reddy NL, Jones TA, Wayte SC, Adesanya O, Sankar S, Yeo YC, et al. Identification of brown adipose tissue using MR imaging in a human adult with histological and immunohistochemical confirmation. J Clin Endocrinol Metab. (2014) 99:E117-121. doi: 10.1210/jc.2013-2036

86. Franz D, Karampinos DC, Rummeny EJ, Souvatzoglou M, Beer AJ, Nekolla SG, et al. Discrimination between brown and white adipose tissue using a 2point dixon water-fat separation method in simultaneous PET/MRI. J Nucl Med. (2015) 56:1742-7. doi: 10.2967/jnumed.115.160770

87. Gifford A, Towse TF, Walker RC, Avison MJ, Welch EB. Characterizing active and inactive brown adipose tissue in adult humans using PET-CT and MR imaging. Am J Physiol Endocrinol Metab. (2016) 311:E95-104. doi: 10.1152/ajpendo.00482.2015

88. Holstila M, Pesola M, Saari T, Koskensalo K, Raiko J, Borra RJ, et al. MR signal-fat-fraction analysis and T2* weighted imaging measure BAT reliably on humans without cold exposure. Metabolism (2017) 70:23-30. doi: 10.1016/j.metabol.2017.02.001

89. Deng J, Neff LM, Rubert NC, Zhang B, Shore RM, Samet JD, et al. MRI characterization of brown adipose tissue under thermal challenges in normal weight, overweight, and obese young men. J Magn Reson Imaging (2018) 47:936-47. doi: 10.1002/jmri.25836

90. Nirengi S, Homma T, Inoue N, Sato H, Yoneshiro T, Matsushita M, et al. Assessment of human brown adipose tissue density during daily ingestion of thermogenic capsinoids using near-infrared time-resolved spectroscopy. $J$ Biomed Opt. (2016) 21:091305. doi: 10.1117/1.JBO.21.9.091305

91. Nirengi S, Yoneshiro T, Saiki T, Aita S, Matsushita M, Sugie $\mathrm{H}$, et al. Evaluation of brown adipose tissue using near-infrared time-resolved spectroscopy. Adv Exp Med Biol. (2016) 876:371-6. doi: 10.1007/978-1-4939-3023-4_46

92. Flynn A, Li Q, Panagia M, Abdelbaky A, Macnabb M, Samir A, et al. Contrast-enhanced ultrasound: a novel noninvasive, nonionizing method for the detection of brown adipose tissue in humans. J Am Soc Echocardiogr. (2015) 28:1247-54. doi: 10.1016/j.echo.2015.06.014

93. Crandall J, O JH, Gajwani P, Leal JP, Mawhinney DD, Sterzer F, et al. Measurement of brown adipose tissue activity using microwave radiometry (MRAD) and FDG PET/CT. J Nucl Med. (2018) doi: 10.2967/jnumed.117.204339 . [Epub ahead of print].
94. Reber J, Willershauser M, Karlas A, Paul-Yuan K, Diot G, Franz D, et al. Non-invasive measurement of brown fat metabolism based on optoacoustic imaging of hemoglobin gradients. Cell Metab (2018) 27:689-701.e684. doi: 10.1016/j.cmet.2018.02.002

95. Bahler L, Holleman F, Booij J, Hoekstra JB, Verberne HJ. Interobserver and intraobserver variability for the assessment of brown adipose tissue activity on 18F-FDG PET-CT. Nucl Med Commun. (2016) 37:363-71. doi: 10.1097/MNM.0000000000000450

96. Sampath SC, Sampath SC, Bredella MA, Cypess AM, Torriani M. Imaging of brown adipose tissue: state of the art. Radiology (2016) 280:4-19. doi: 10.1148/radiol.2016150390

97. Becker AS, Zellweger C, Schawkat K, Bogdanovic S, Phi Van VD, Nagel HW, et al. In-depth analysis of interreader agreement and accuracy in categorical assessment of brown adipose tissue in (18)FDG-PET/CT. Eur J Radiol. (2017) 91:41-6. doi: 10.1016/j.ejrad.2017.03.012

98. Chondronikola M, Beeman SC, Wahl RL. Non-invasive methods for the assessment of brown adipose tissue in humans. J Physiol. (2018) 596:363-78. doi: 10.1113/JP274255

99. Ong FJ, Ahmed BA, Oreskovich SM, Blondin DP, Haq T, Konyer NB, et al. Recent advances in the detection of brown adipose tissue in adult humans: a review. Clin Sci. (2018) 132:1039-54. doi: 10.1042/CS20170276

100. Hankir MK, Cowley MA, Fenske WK. A BAT-centric approach to the treatment of diabetes: turn on the brain. Cell Metab. (2016) 24:31-40. doi: 10.1016/j.cmet.2016.05.003

101. Giralt M, Villarroya F. Mitochondrial uncoupling and the regulation of glucose homeostasis. Curr Diabetes Rev. (2017) 13:386-94. doi: 10.2174/1573399812666160217122707

102. Blauw LL, Aziz NA, Tannemaat MR, Blauw CA, De Craen AJ, Pijl H, et al. Diabetes incidence and glucose intolerance prevalence increase with higher outdoor temperature. BMJ Open Diabetes Res Care (2017) 5:e000317. doi: 10.1136/bmjdrc-2016-000317

103. Booth GL, Luo J, Park AL, Feig DS, Moineddin R, Ray JG. Influence of environmental temperature on risk of gestational diabetes. CMAJ (2017) 189:E682-9. doi: 10.1503/cmaj.160839

104. Chondronikola M, Volpi E, Borsheim E, Porter C, Annamalai P, Enerback S, et al. Brown adipose tissue improves whole-body glucose homeostasis and insulin sensitivity in humans. Diabetes (2014) 63:4089-99. doi: $10.2337 / \mathrm{db} 14-0746$

105. Hanssen MJ, Hoeks J, Brans B, Van Der Lans AA, Schaart G, Van Den Driessche JJ, et al. Short-term cold acclimation improves insulin sensitivity in patients with type 2 diabetes mellitus. Nat Med. (2015b) 21:863-5. doi: $10.1038 / \mathrm{nm} .3891$

106. Iwen KA, Backhaus J, Cassens M, Waltl M, Hedesan OC, Merkel M, et al. Cold-induced brown adipose tissue activity alters plasma fatty acids and improves glucose metabolism in men. J Clin Endocrinol Metab. (2017) 102:4226-34. doi: 10.1210/jc.2017-01250

107. Blondin DP, Labbe SM, Phoenix S, Guerin B, Turcotte EE, Richard D, et al. Contributions of white and brown adipose tissues and skeletal muscles to acute cold-induced metabolic responses in healthy men. J Physiol. (2015) 593:701-14. doi: 10.1113/jphysiol.2014.283598

108. Ouellet V, Labbe SM, Blondin DP, Phoenix S, Guerin B, Haman F, et al. Brown adipose tissue oxidative metabolism contributes to energy expenditure during acute cold exposure in humans. J Clin Invest. (2012) 122:545-52. doi: 10.1172/JCI60433

109. Blondin DP, Labbe SM, Noll C, Kunach M, Phoenix S, Guerin B, et al. Selective impairment of glucose but not fatty acid or oxidative metabolism in brown adipose tissue of subjects with type 2 Diabetes (2015) 64:2388-97. doi: $10.2337 / \mathrm{db} 14-1651$

110. Noll C, Carpentier AC. Dietary fatty acid metabolism in prediabetes. Curr Opin Lipidol. (2017) 28:1-10. doi: 10.1097/MOL.0000000000000369

111. Orava J, Nuutila P, Lidell ME, Oikonen V, Noponen T, Viljanen $\mathrm{T}$, et al. Different metabolic responses of human brown adipose tissue to activation by cold and insulin. Cell Metab. (2011) 14:272-9. doi: 10.1016/j.cmet.2011.06.012

112. Orava J, Nuutila P, Noponen T, Parkkola R, Viljanen T, Enerback $\mathrm{S}$, et al. Blunted metabolic responses to cold and insulin stimulation in brown adipose tissue of obese humans. Obesity (2013) 21:2279-87. doi: 10.1002/oby.20456 
113. Blondin DP, Daoud A, Taylor T, Tingelstad HC, Bezaire V, Richard D, et al. Four-week cold acclimation in adult humans shifts uncoupling thermogenesis from skeletal muscles to brown adipose tissue. J Physiol. (2017) 595:2099-113. doi: 10.1113/JP273395

114. Dadson P, Hannukainen JC, Din MU, Lahesmaa M, Kalliokoski KK, Iozzo $\mathrm{P}$, et al. Brown adipose tissue lipid metabolism in morbid obesity: effect of bariatric surgery-induced weight loss. Diabetes Obes Metab. (2018) 20:12808. doi: 10.1111/dom.13233

115. Blondin DP, Tingelstad HC, Noll C, Frisch F, Phoenix S, Guerin B, et al. Dietary fatty acid metabolism of brown adipose tissue in cold-acclimated men. Nat Commun. (2017) 8:14146. doi: 10.1038/ncomms14146

116. Weir G, Ramage LE, Akyol M, Rhodes JK, Kyle CJ, Fletcher AM, et al. Substantial metabolic activity of human brown adipose tissue during warm conditions and cold-induced lipolysis of local triglycerides. Cell Metab. (2018) 27:1348-55.e4. doi: 10.1016/j.cmet.2018.04.020

117. Wang Q, Zhang M, Ning G, Gu W, Su T, Xu M, et al. Brown adipose tissue in humans is activated by elevated plasma catecholamines levels and is inversely related to central obesity. PLoS ONE (2011) 6:e21006. doi: 10.1371/journal.pone.0021006

118. Bahler L, Verberne HJ, Admiraal WM, Stok WJ, Soeters MR, Hoekstra JB, et al. Differences in sympathetic nervous stimulation of brown adipose tissue between the young and old, and the lean and obese. J Nucl Med. (2016) 57:372-7. doi: 10.2967/jnumed.115.165829

119. Ulaner GA, Samstein R, Cahlon O, Weber WA, Rimner A. Unilateral suppression of brown fat on FDG PET/CT in horner syndrome. Clin Nucl Med. (2016) 41:797-8. doi: 10.1097/RLU.0000000000001319

120. Hankir MK, Kranz M, Keipert S, Weiner J, Andreasen SG, Kern M, et al. Dissociation between brown adipose tissue (18)F-FDG uptake and thermogenesis in uncoupling protein 1-deficient mice. J Nucl Med. (2017) 58:1100-3. doi: 10.2967/jnumed.116.186460

121. Olsen JM, Csikasz RI, Dehvari N, Lu L, Sandstrom A, Oberg AI, et al. beta3-Adrenergically induced glucose uptake in brown adipose tissue is independent of UCP1 presence or activity: Mediation through the mTOR pathway. Mol Metab. (2017) 6:611-9. doi: 10.1016/j.molmet.2017.02.006

122. Ma SW, Foster DO. Uptake of glucose and release of fatty acids and glycerol by rat brown adipose tissue in vivo. Can J Physiol Pharmacol. (1986) 64:609-14. doi: 10.1139/y86-101

123. Reshef L, Olswang Y, Cassuto H, Blum B, Croniger CM, Kalhan SC, et al. Glyceroneogenesis and the triglyceride/fatty acid cycle. J BiolChem. (2003) 278:30413-6. doi: 10.1074/jbc.R300017200

124. Cypess AM, Doyle AN, Sass CA, Huang TL, Mowschenson PM, Rosen $\mathrm{HN}$, et al. Quantification of human and rodent brown adipose tissue function using 99mTc-methoxyisobutylisonitrile SPECT/CT and 18F-FDG PET/CT. J Nucl Med. (2013) 54:1896-901. doi: 10.2967/jnumed.113.1 21012

125. Latva-Rasku A, Honka MJ, Stancakova A, Koistinen HA, Kuusisto J, Guan L, et al. A partial loss-of-function variant in AKT2 is associated with reduced insulin-mediated glucose uptake in multiple insulin-sensitive tissues: a genotype-based callback positron emission tomography study. Diabetes (2018) 67:334-42. doi: 10.2337/db17-1142

126. Thuzar M, Law WP, Ratnasingam J, Jang C, Dimeski G, Ho KKY. Glucocorticoids suppress brown adipose tissue function in humans: a double-blind placebo-controlled study. Diabetes Obes Metab. (2018) 20:8408. doi: 10.1111/dom.13157

127. Hanssen MJ, Wierts R, Hoeks J, Gemmink A, Brans B, Mottaghy FM, et al. Glucose uptake in human brown adipose tissue is impaired upon fasting-induced insulin resistance. Diabetologia (2015) 58:586-95. doi: 10.1007/s00125-014-3465-8

128. Carey AL, Pajtak R, Formosa MF, Van Every B, Bertovic DA, Anderson MJ, et al. Chronic ephedrine administration decreases brown adipose tissue activity in a randomised controlled human trial: implications for obesity. Diabetologia (2015) 58:1045-54. doi: 10.1007/s00125-015-3543-6

129. Vijgen GH, Bouvy ND, Teule GJ, Brans B, Hoeks J, Schrauwen P, et al. Increase in brown adipose tissue activity after weight loss in morbidly obese subjects. J Clin Endocrinol Metab. (2012) 97:E1229-33. doi: 10.1210/jc.2012-1289

130. Rachid B, Van De Sande-Lee S, Rodovalho S, Folli F, Beltramini GC, Morari J, et al. Distinct regulation of hypothalamic and brown/beige adipose tissue activities in human obesity. Int J Obes. (2015) 39:1515-22. doi: 10.1038/ijo.2015.94

131. Motiani P, Virtanen KA, Motiani KK, Eskelinen JJ, Middelbeek RJ, Goodyear LJ, et al. Decreased insulin-stimulated brown adipose tissue glucose uptake after short-term exercise training in healthy middle aged men. Diabetes Obes Metab. (2017) 19:1379-88. doi: 10.1111/dom.12947

132. Koskensalo K, Raiko J, Saari T, Saunavaara V, Eskola O, Nuutila P, et al Human brown adipose tissue temperature and fat fraction are related to its metabolic activity. J Clin Endocrinol Metab. (2017) 102:1200-7. doi: 10.1210/jc.2016-3086

133. Grenier-Larouche TL, Noll C, Richard D, Carpentier AC. Metabolic inflexibility of white and brown adipose tissues in abnormal fatty acid partitioning of type 2 diabetes. Int J Obesity (2012) 2:S37-42. doi: 10.1038/ijosup.2012.21

134. Chondronikola M, Volpi E, Borsheim E, Porter C, Saraf MK, Annamalai $\mathrm{P}$, et al. Brown adipose tissue activation is linked to distinct systemic effects on lipid metabolism in humans. Cell Metab. (2016) 23:1200-6. doi: 10.1016/j.cmet.2016.04.029

135. Lee P, Zhao JT, Swarbrick MM, Gracie G, Bova R, Greenfield JR, et al. High prevalence of brown adipose tissue in adult humans. J Clin Endocrinol Metab. (2011) 96:2450-5. doi: 10.1210/jc.2011-0487

136. Carpentier AC, Labbe SM, Grenier-Larouche T, Noll C. Abnormal dietary fatty acid metabolic partitioning in insulin resistance and type 2 diabetes. Clin Lipidol. (2011) 6:703-16. doi: 10.2217/clp.11.60

137. Hames KC, Vella A, Kemp BJ, Jensen MD. Free fatty acid uptake in humans with CD36 deficiency. Diabetes (2014) 63:3606-14. doi: 10.2337/db14-0369

138. Labbe SM, Croteau E, Grenier-Larouche T, Frisch F, Ouellet R, Langlois R, et al. Normal postprandial nonesterified fatty acid uptake in muscles despite increased circulating fatty acids in type 2 diabetes. Diabetes (2011) 60:408-15. doi: $10.2337 / \mathrm{db} 10-0997$

139. Bjornson E, Adiels M, Taskinen MR, Boren J. Kinetics of plasma triglycerides in abdominal obesity. Curr Opin Lipidol. (2017) 28:11-8. doi: 10.1097/MOL.0000000000000375

140. Goldberg IJ, Eckel RH, Abumrad NA. Regulation of fatty acid uptake into tissues: lipoprotein lipase- and CD36-mediated pathways. J.Lipid Res. (2009) 50(Suppl.):S86-90. doi: 10.1194/jlr.R800085-JLR200

141. Hoeke G, Nahon KJ, Bakker LEH, Norkauer SSC, Dinnes DLM, Kockx $\mathrm{M}$, et al. Short-term cooling increases serum triglycerides and small highdensity lipoprotein levels in humans. J Clin Lipidol. (2017) 11:920-928.e922. doi: 10.1016/j.jacl.2017.04.117

142. Ci X, Frisch F, Lavoie F, Germain P, Lecomte R, Van Lier JE, et al. The effect of insulin on the intracellular distribution of $14(\mathrm{R}, \mathrm{S})-[(18) \mathrm{F}]$ Fluoro6-thia-heptadecanoic acid in rats. Mol Imaging Biol. (2006) 8:237-44. doi: 10.1007/s11307-006-0042-7

143. U. Din M, Raiko J, Saari T, Kudomi N, Tolvanen T, Oikonen V, et al. Human brown adipose tissue [(15)O]O2 PET imaging in the presence and absence of cold stimulus. Eur J Nucl Med Mol Imaging (2016) 43:1878-86. doi: 10.1007/s00259-016-3364-y

144. Bartelt A, Bruns OT, Reimer R, Hohenberg H, Ittrich H, Peldschus K, et al. Brown adipose tissue activity controls triglyceride clearance. Nat Med. (2011) 17:200-5. doi: 10.1038/nm.2297

145. Hoeke G, Kooijman S, Boon MR, Rensen PC, Berbee JF. Role of brown fat in lipoprotein metabolism and atherosclerosis. Circ Res. (2016) 118:173-82. doi: 10.1161/CIRCRESAHA.115.306647

146. Dijk W, Heine M, Vergnes L, Boon MR, Schaart G, Hesselink MK, et al. ANGPTL4 mediates shuttling of lipid fuel to brown adipose tissue during sustained cold exposure. Elife (2015) 4:e08428. doi: 10.7554/eLife.08428

147. Hoeke G, Wang Y, Van Dam AD, Mol IM, Gart E, Klop $\mathrm{HG}$, et al. Atorvastatin accelerates clearance of lipoprotein remnants generated by activated brown fat to further reduce hypercholesterolemia and atherosclerosis. Atherosclerosis (2017) 267:116-26. doi: 10.1016/j.atherosclerosis.2017.10.030

148. Shao X, Yang W, Shao X, Qiu C, Wang X, Wang Y. The role of active brown adipose tissue (aBAT) in lipid metabolism in healthy Chinese adults. Lipids Health Dis. (2016) 15:138. doi: 10.1186/s12944-016-0310-8

149. Labbe SM, Grenier-Larouche T, Croteau E, Normand-Lauziere F, Frisch F, Ouellet R, et al. Organ-specific dietary fatty acid uptake in humans using positron emission tomography coupled to computed 
tomography. Am J Physiol Endocrinol Metab (2011) 300:E445-53. doi: 10.1152/ajpendo.00579.2010

150. Lynes MD, Leiria LO, Lundh M, Bartelt A, Shamsi F, Huang TL, et al. The cold-induced lipokine 12,13-diHOME promotes fatty acid transport into brown adipose tissue. Nat Med. (2017) 23:631-7. doi: 10.1038/nm.4297

151. Boon MR, Bakker LEH, Prehn C, Adamski J, Vosselman MJ, Jazet IM, et al. LysoPC-acyl C16:0 is associated with brown adipose tissue activity in men. Metabolomics (2017) 13:48. doi: 10.1007/s11306-017-1185-Z

152. Chakrabarty K, Chaudhuri B, Jeffay H. Glycerokinase activity in human brown adipose tissue. J Lipid Res. (1983) 24:381-90.

153. Kawashita NH, Festuccia WT, Brito MN, Moura MA, Brito SR, Garofalo MA, et al. Glycerokinase activity in brown adipose tissue: a sympathetic regulation? Am J Physiol Regul Integr Comp Physiol. (2002) 282:R1185-90. doi: 10.1152/ajpregu.00419.2001

154. Festuccia WT, Kawashita NH, Garofalo MA, Moura MA, Brito SR, Kettelhut IC, et al. Control of glyceroneogenic activity in rat brown adipose tissue. AmJ Physiol Regul Integr Comp Physiol. (2003) 285:R177-82. doi: 10.1152/ajpregu.00713.2002

155. Lasar D, Rosenwald M, Kiehlmann E, Balaz M, Tall B, Opitz L, et al. Peroxisome proliferator activated receptor gamma controls mature brown adipocyte inducibility through glycerol kinase. Cell Rep. (2018) 22:760-73. doi: 10.1016/j.celrep.2017.12.067

156. Lopaschuk GD. Metabolic modulators in heart disease: past, present, and future. Can J Cardiol. (2017) 33:838-49. doi: 10.1016/j.cjca.2016.12.013

157. U. Din M, Raiko J, Saari T, Saunavaara V, Kudomi N, Solin O, et al. Human brown fat radiodensity indicates underlying tissue composition and systemic metabolic health. J Clin Endocrinol Metab (2017) 102:2258-67. doi: 10.1210/jc.2016-2698

158. Mccallister A, Zhang L, Burant A, Katz L, Branca RT. A pilot study on the correlation between fat fraction values and glucose uptake values in supraclavicular fat by simultaneous PET/MRI. Magn Reson Med. (2017) 78:1922-32. doi: 10.1002/mrm.26589

159. Raiko J, Holstila M, Virtanen KA, Orava J, Saunavaara V, Niemi T, et al. Brown adipose tissue triglyceride content is associated with decreased insulin sensitivity, independently of age and obesity. Diabetes Obes Metab. (2015) 17:516-9. doi: 10.1111/dom. 12433

160. Baba S, Jacene HA, Engles JM, Honda H, Wahl RL. CT hounsfield units of brown adipose tissue increase with activation: preclinical and clinical studies. J Nucl Med. (2010) 51:246-50. doi: 10.2967/jnumed.109.068775

161. Lundstrom E, Strand R, Johansson L, Bergsten P, Ahlstrom H, Kullberg J. Magnetic resonance imaging cooling-reheating protocol indicates decreased fat fraction via lipid consumption in suspected brown adipose tissue. PLoS ONE (2015) 10:e0126705. doi: 10.1371/journal.pone.0126705

162. Mottillo EP, Desjardins EM, Crane JD, Smith BK, Green AE, Ducommun $\mathrm{S}$, et al. Lack of adipocyte AMPK exacerbates insulin resistance and hepatic steatosis through brown and beige adipose tissue function. Cell Metab. (2016) 24:118-29. doi: 10.1016/j.cmet.2016.06.006

163. Carpentier A, Frisch F, Cyr D, Genereux P, Patterson BW, Giguere R, et al. On the suppression of plasma non-esterified fatty acids by insulin during enhanced intravascular lipolysis in humans. Am J Physiol Endocrinol Metab. (2005) 289:E849-56. doi: 10.1152/ajpendo.00073.2005

164. Vijgen GH, Bouvy ND, Teule GJ, Brans B, Schrauwen P, Van Marken Lichtenbelt WD. Brown adipose tissue in morbidly obese subjects. PLoS ONE (2011) 6:e17247. doi: 10.1371/journal.pone.0017247

165. Yoneshiro T, Aita S, Matsushita M, Kameya T, Nakada K, Kawai Y, et al. Brown adipose tissue, whole-body energy expenditure, and thermogenesis in healthy adult men. Obesity (2011) 19:13-6. doi: 10.1038/oby.2010.105

166. Yoneshiro T, Matsushita M, Nakae S, Kameya T, Sugie H, Tanaka S, et al. Brown adipose tissue is involved in the seasonal variation of coldinduced thermogenesis in humans. Am J Physiol Regul Integr Comp Physiol. (2016) 310:R999-1009. doi: 10.1152/ajpregu.00057.2015

167. Chondronikola M, Volpi E, Borsheim E, Chao T, Porter C, Annamalai $\mathrm{P}$, et al. Brown adipose tissue is linked to a distinct thermoregulatory response to mild cold in people. Front Physiol (2016) 7:129. doi: 10.3389/fphys.2016.00129

168. Chen KY, Brychta RJ, Linderman JD, Smith S, Courville A, Dieckmann W, et al. Brown fat activation mediates cold-induced thermogenesis in adult humans in response to a mild decrease in ambient temperature. $J$ Clin Endocrinol Metab. (2013) 98:E1218-23. doi: 10.1210/jc.2012-4213

169. Yoneshiro T, Aita S, Matsushita M, Okamatsu-Ogura Y, Kameya T, Kawai $\mathrm{Y}$, et al. Age-related decrease in cold-activated brown adipose tissue and accumulation of body fat in healthy humans. Obesity (2011) 19:1755-60. doi: 10.1038/oby.2011.125

170. Bakker LE, Boon MR, Van Der Linden RA, Arias-Bouda LP, Van Klinken JB, Smit F, et al. Brown adipose tissue volume in healthy lean south Asian adults compared with white Caucasians: a prospective, casecontrolled observational study. Lancet Diabetes Endocrinol. (2014) 2:210-7. doi: 10.1016/S2213-8587(13)70156-6

171. Yilmaz Y, Ones T, Purnak T, Ozguven S, Kurt R, Atug O, et al. Association between the presence of brown adipose tissue and non-alcoholic fatty liver disease in adult humans. Aliment Pharmacol Ther. (2011) 34:318-23. doi: 10.1111/j.1365-2036.2011.04723.x

172. Vosselman MJ, Hoeks J, Brans B, Pallubinsky H, Nascimento EB, Van Der Lans AA, et al. Low brown adipose tissue activity in endurancetrained compared with lean sedentary men. Int J Obes. (2015) 39:1696-702. doi: 10.1038/ijo.2015.130

173. Singhal V, Maffazioli GD, Ackerman KE, Lee H, Elia EF, Woolley R, et al. Effect of chronic athletic activity on brown fat in young women. PLOS ONE (2016) 11:e0156353. doi: 10.1371/journal.pone.0156353

174. Yoneshiro T, Ogawa T, Okamoto N, Matsushita M, Aita S, Kameya T, et al. Impact of UCP1 and beta3AR gene polymorphisms on age-related changes in brown adipose tissue and adiposity in humans. Int J Obes. (2013) 37:993-8. doi: 10.1038/ijo.2012.161

175. Laurila PP, Soronen J, Kooijman S, Forsstrom S, Boon MR, Surakka I, et al. USF1 deficiency activates brown adipose tissue and improves cardiometabolic health. Sci Transl Med. (2016) 8:323ra313. doi: 10.1126/scitranslmed.aad0015

176. Lee P, Smith S, Linderman J, Courville AB, Brychta RJ, Dieckmann W, et al. Temperature-acclimated brown adipose tissue modulates insulin sensitivity in humans. Diabetes (2014) 63:3686-98. doi: 10.2337/db14-0513

177. Yoneshiro T, Aita S, Kawai Y, Iwanaga T, Saito M. Nonpungent capsaicin analogs (capsinoids) increase energy expenditure through the activation of brown adipose tissue in humans. Am J Clin Nutr. (2012) 95:845-50. doi: 10.3945/ajen.111.018606

178. Yoneshiro T, Matsushita M, Hibi M, Tone H, Takeshita M, Yasunaga K, et al. Tea catechin and caffeine activate brown adipose tissue and increase cold-induced thermogenic capacity in humans. Am J Clin Nutr. (2017) 105:873-81. doi: 10.3945/ajcn.116.144972

179. Vijgen GH, Bouvy ND, Leenen L, Rijkers K, Cornips E, Majoie $M$, et al. Vagus nerve stimulation increases energy expenditure: relation to brown adipose tissue activity. PLOS ONE (2013) 8:e77221. doi: 10.1371/journal.pone.0077221

180. Carey AL, Formosa MF, Van Every B, Bertovic D, Eikelis N, Lambert GW, et al. Ephedrine activates brown adipose tissue in lean but not obese humans. Diabetologia (2013) 56:147-55. doi: 10.1007/s00125-012-2748-1

181. Cypess AM, Chen YC, Sze C, Wang K, English J, Chan O, et al. Cold but not sympathomimetics activates human brown adipose tissue in vivo. Proc Natl Acad Sci USA. (2012) 109:10001-5. doi: 10.1073/pnas.1207911109

182. Vosselman MJ, Van Der Lans AA, Brans B, Wierts R, Van Baak MA, Schrauwen $\mathrm{P}$, et al. Systemic beta-adrenergic stimulation of thermogenesis is not accompanied by brown adipose tissue activity in humans. Diabetes (2012) 61:3106-13. doi: 10.2337/db12-0288

183. Cypess AM, Weiner LS, Roberts-Toler C, Franquet Elia E, Kessler SH, Kahn $\mathrm{PA}$, et al. Activation of human brown adipose tissue by a beta3-adrenergic receptor agonist. Cell Metab. (2015) 21:33-8. doi: 10.1016/j.cmet.2014.12.009

184. Lahesmaa M, Orava J, Schalin-Jantti C, Soinio M, Hannukainen JC, Noponen T, et al. Hyperthyroidism increases brown fat metabolism in humans. J Clin Endocrinol Metab. (2014) 99:E28-35. doi: 10.1210/jc.2013-2312

185. Zhang Q, Miao Q, Ye H, Zhang Z, Zuo C, Hua F, et al. The effects of thyroid hormones on brown adipose tissue in humans: a PET-CT study. Diabetes Metab Res Rev. (2014) 30:513-20. doi: 10.1002/dmrr.2556

186. Gavrila A, Hasselgren PO, Glasgow A, Doyle AN, Lee AJ, Fox P, et al. Variable cold-induced brown adipose tissue response to Thyroid hormone status. Thyroid (2017) 27:1-10. doi: 10.1089/thy.2015.0646 
187. Beijer E, Schoenmakers J, Vijgen G, Kessels F, Dingemans AM, Schrauwen $\mathrm{P}$, et al. A role of active brown adipose tissue in cancer cachexia? Oncol Rev. (2012) 6:e11. doi: 10.4081/oncol.2012.e11

188. De Vos-Geelen J, Fearon KC, Schols AM. The energy balance in cancer cachexia revisited. Curr Opin Clin Nutr Metab Care (2014) 17:509-14. doi: 10.1097/MCO.0000000000000106

189. Chalfant JS, Smith ML, Hu HH, Dorey FJ, Goodarzian F, Fu CH, et al. Inverse association between brown adipose tissue activation and white adipose tissue accumulation in successfully treated pediatric malignancy. Am J Clin Nutr. (2012) 95:1144-9. doi: 10.3945/ajcn.111.030650

190. Gadea E, Thivat E, Merlin C, Paulon R, Kwiatkowski F, Chadeyras JB, et al. Brown adipose tissue activity in relation to weight gain during chemotherapy in breast cancer patients: a pilot study. Nutr Cancer (2014) 66:1092-6. doi: 10.1080/01635581.2014.948212

191. Carpentier AC. Acute adaptation of energy expenditure predicts dietinduced weight loss: revisiting the thrifty phenotype. Diabetes (2015) 64:2714-6. doi: 10.2337/db15-0553

192. Hibi M, Oishi S, Matsushita M, Yoneshiro T, Yamaguchi T, Usui C, et al. Brown adipose tissue is involved in diet-induced thermogenesis and wholebody fat utilization in healthy humans. Int J Obes. (2016) 40:1655-61. doi: 10.1038/ijo.2016.124

193. Vosselman MJ, Brans B, Van Der Lans AA, Wierts R, Van Baak MA, Mottaghy FM, et al. Brown adipose tissue activity after a high-calorie meal in humans. Am J Clin Nutr. (2013) 98:57-64. doi: 10.3945/ajcn.113.059022

194. Thearle MS, Pannacciulli N, Bonfiglio S, Pacak K, Krakoff J. Extent and determinants of thermogenic responses to 24 hours of fasting, energy balance, and five different overfeeding diets in humans. J Clin Endocrinol Metab. (2013) 98:2791-9. doi: 10.1210/jc.2013-1289

195. Schlogl M, Piaggi P, Thiyyagura P, Reiman EM, Chen K, Lutrin C, et al. Overfeeding over 24 hours does not activate brown adipose tissue in humans. J Clin Endocrinol Metab. (2013) 98:E1956-1960. doi: 10.1210/jc.2013-2387

196. U. Din M, Saari T, Raiko J, Kudomi N, Maurer SF, Lahesmaa $\mathrm{M}$, et al. Postprandial oxidative metabolism of human brown fat indicates thermogenesis. Cell Metab. (2018). doi: 10.1016/j.cmet.2018.05.020. [Epub ahead of print].

197. Young JB, Landsberg L. Suppression of sympathetic nervous system during fasting. Obes Res. (1997) 5:646-9. doi: 10.1002/j.1550-8528.1997.tb00590.x

198. Vijgen GH, Sparks LM, Bouvy ND, Schaart G, Hoeks J, Van Marken Lichtenbelt WD, et al. Increased oxygen consumption in human adipose tissue from the "brown adipose tissue" region. J Clin Endocrinol Metab. (2013) 98:E1230-4. doi: 10.1210/jc.2013-1348

199. Muzik O, Mangner TJ, Granneman JG. Assessment of oxidative metabolism in brown fat using PET imaging. Front Endocrinol. (2012) 3:15. doi: $10.3389 /$ fendo.2012.00015

200. Muzik O, Mangner TJ, Leonard WR, Kumar A, Janisse J, Granneman JG. 15O PET measurement of blood flow and oxygen consumption in cold-activated human brown fat. J Nucl Med. (2013) 54:523-31. doi: 10.2967/jnumed.112.111336

201. Leonard WR. Measuring human energy expenditure and metabolic function: basic principles and methods. J Anthropol Sci. (2010) 88:221-30.

202. Martin AD, Daniel MZ, Drinkwater DT, Clarys JP. Adipose tissue density, estimated adipose lipid fraction and whole body adiposity in male cadavers. Int J Obes Relat Metab Disord. (1994) 18:79-83.

203. Keipert S, Jastroch M. Brite/beige fat and UCP1 - is it thermogenesis? Biochim Biophys Acta (2014) 1837:1075-82.

204. Kiefer FW. Browning and thermogenic programing of adipose tissue. Best Pract Res Clin Endocrinol Metab. (2016) 30:479-85. doi: 10.1016/j.beem.2016.09.003

205. Castro E, Silva TEO, Festuccia WT. Critical review of beige adipocyte thermogenic activation and contribution to whole-body energy expenditure. Horm Mol Biol Clin Investig. (2017) 31. doi: 10.1515/hmbci-201 7-0042

206. Sepa-Kishi DM, Ceddia RB. White and beige adipocytes: are they metabolically distinct? Horm Mol Biol Clin Investig (2018) 33. doi: 10.1515/hmbci-2018-0003

207. $\mathrm{Hu} \mathrm{J}$, Christian M. Hormonal factors in the control of the browning of white adipose tissue. Horm Mol Biol Clin Investig (2017) 31. doi: 10.1515/hmbci-2017-0017
208. Aldiss P, Betts J, Sale C, Pope M, Budge H, Symonds ME. Exerciseinduced 'browning' of adipose tissues. Metabolism (2018) 81:63-70. doi: 10.1016/j.metabol.2017.11.009

209. Seale P, Conroe HM, Estall J, Kajimura S, Frontini A, Ishibashi J, et al. Prdm16 determines the thermogenic program of subcutaneous white adipose tissue in mice. J Clin Invest. (2011) 121:96-105. doi: 10.1172/JCI44271

210. Morroni M, Barbatelli G, Zingaretti MC, Cinti S. Immunohistochemical, ultrastructural and morphometric evidence for brown adipose tissue recruitment due to cold acclimation in old rats. Int J Obes Relat Metab Disord. (1995) 19:126-31.

211. Bostrom P, Wu J, Jedrychowski MP, Korde A, Ye L, Lo JC, et al. A PGC1-alpha-dependent myokine that drives brown-fat-like development of white fat and thermogenesis. Nature (2012) 481:463-8. doi: 10.1038/nature 10777

212. Ohno H, Shinoda K, Spiegelman BM, Kajimura S. PPARgamma agonists induce a white-to-brown fat conversion through stabilization of PRDM16 protein. Cell Metab. (2012) 15:395-404. doi: 10.1016/j.cmet.2012.01.019

213. Labbe SM, Caron A, Chechi K, Laplante M, Lecomte R, Richard D. Metabolic activity of brown, "beige," and white adipose tissues in response to chronic adrenergic stimulation in male mice. Am J Physiol Endocrinol Metab. (2016) 311:E260-8. doi: 10.1152/ajpendo.00545.2015

214. Sbarbati A, Morroni M, Zancanaro C, Cinti S. Rat interscapular brown adipose tissue at different ages: a morphometric study. Int J Obes. (1991) 15:581-7.

215. Zingaretti MC, Crosta F, Vitali A, Guerrieri M, Frontini A, Cannon B, et al. The presence of UCP1 demonstrates that metabolically active adipose tissue in the neck of adult humans truly represents brown adipose tissue. FASEB J. (2009) 23:3113-20. doi: 10.1096/fj.09-133546

216. Nedergaard J, Bengtsson T, Cannon B. Three years with adult human brown adipose tissue. AnnNYAcadSci. (2010) 1212:E20-36. doi: 10.1111/j.1749-6632.2010.05905.x

217. Van Den Beukel JC, Grefhorst A, Hoogduijn MJ, Steenbergen J, Mastroberardino PG, Dor FJ, et al. Women have more potential to induce browning of perirenal adipose tissue than men. Obesity (2015) 23:1671-9. doi: 10.1002/oby.21166

218. Sondergaard E, Gormsen LC, Christensen MH, Pedersen SB, Christiansen $\mathrm{P}$, Nielsen $\mathrm{S}$, et al. Chronic adrenergic stimulation induces brown adipose tissue differentiation in visceral adipose tissue. Diabet Med. (2015) 32:e4-8. doi: 10.1111/dme.12595

219. Berthiaume M, Sell H, Lalonde J, Gelinas Y, Tchernof A, Richard D, et al. Actions of PPARgamma agonism on adipose tissue remodeling, insulin sensitivity, and lipemia in absence of glucocorticoids. Am J Physiol Regul Integr Comp Physiol. (2004) 287:R1116-23. doi: 10.1152/ajpregu.00339.2004

220. Festuccia WT, Oztezcan S, Laplante M, Berthiaume M, Michel C, Dohgu S, et al. Peroxisome proliferator-activated receptor-gamma-mediated positive energy balance in the rat is associated with reduced sympathetic drive to adipose tissues and thyroid status. Endocrinology (2008) 149:2121-30. doi: 10.1210/en.2007-1553

221. Festuccia WT, Blanchard PG, Oliveira TB, Magdalon J, Paschoal VA, Richard D, et al. PPARgamma activation attenuates cold-induced upregulation of thyroid status and brown adipose tissue PGC-1alpha and D2. Am J Physiol Regul Integr Comp Physiol. (2012) 303:R1277-85. doi: 10.1152/ajpregu.00299.2012

222. Loh RKC, Formosa MF, Eikelis N, Bertovic DA, Anderson MJ, Barwood $\mathrm{SA}$, et al. Pioglitazone reduces cold-induced brown fat glucose uptake despite induction of browning in cultured human adipocytes: a randomised, controlled trial in humans. Diabetologia (2018) 61:220-30. doi: 10.1007/s00125-017-4479-9

223. Shabalina IG, Petrovic N, De Jong JM, Kalinovich AV, Cannon B, Nedergaard J. UCP1 in brite/beige adipose tissue mitochondria is functionally thermogenic. Cell Rep. (2013) 5:1196-203. doi: 10.1016/j.celrep.2013.10.044

224. Kalinovich AV, De Jong JM, Cannon B, Nedergaard J. UCP1 in adipose tissues: two steps to full browning. Biochimie (2017) 134:127-37. doi: 10.1016/j.biochi.2017.01.007

225. Kazak L, Chouchani ET, Jedrychowski MP, Erickson BK, Shinoda K, Cohen $\mathrm{P}$, et al. A creatine-driven substrate cycle enhances energy expenditure and thermogenesis in beige fat. Cell (2015) 163:643-55. doi: 10.1016/j.cell.2015.09.035 
226. Ikeda K, Kang Q, Yoneshiro T, Camporez JP, Maki H, Homma M, et al. UCP1-independent signaling involving SERCA2b-mediated calcium cycling regulates beige fat thermogenesis and systemic glucose homeostasis. Nat Med. (2017) 23:1454-65. doi: 10.1038/nm.4429

227. Ukropec J, Anunciado RP, Ravussin Y, Hulver MW, Kozak LP. UCP1independent thermogenesis in white adipose tissue of cold-acclimated Ucp1/- mice. JBiolChem. (2006) 281:31894-908. doi: 10.1074/jbc.M606114200

228. Flachs P, Rossmeisl M, Kuda O, Kopecky J. Stimulation of mitochondrial oxidative capacity in white fat independent of UCP1: a key to lean phenotype. Biochim Biophys Acta (2013) 1831:986-1003. doi: 10.1016/j.bbalip.2013.02.003

229. Grenier-Larouche T, Carreau AM, Geloen A, Frisch F, Biertho L, Marceau S, et al. Fatty Acid metabolic remodeling during type 2 diabetes remission after bariatric surgery. Diabetes (2017) 66:2743-55. doi: 10.2337/db17-0414

230. Hivert MF, Langlois MF, Berard P, Cuerrier JP, Carpentier AC. Prevention of weight gain in young adults through a seminar-based intervention program. Int J Obes. (2007) 31:1262-9. doi: 10.1038/sj.ijo.0803572

231. Dutton GR, Kim Y, Jacobs DR Jr, Li X, Loria CM, Reis JP, et al. 25-year weight gain in a racially balanced sample of U.S. adults: The CARDIA study. Obesity (2016) 24:1962-8. doi: 10.1002/oby.21573

232. Sanghvi A, Redman LM, Martin CK, Ravussin E, Hall KD. Validation of an inexpensive and accurate mathematical method to measure long-term changes in free-living energy intake. Am J Clin Nutr. (2015) 102:353-8. doi: 10.3945/ajcn.115.111070

233. Reinhardt M, Thearle MS, Ibrahim M, Hohenadel MG, Bogardus C, Krakoff J, et al. A human thrifty phenotype associated with less weight loss during caloric restriction. Diabetes (2015) 64:2859-67. doi: 10.2337/db14-1881

234. Nguyen KT, Billington CJ, Vella A, Wang Q, Ahmed L, Bantle JP, et al. Preserved insulin secretory capacity and weight loss are the predominant predictors of glycemic control in patients with type 2 diabetes randomized to Roux-en-Y gastric bypass. Diabetes (2015) 64:3104-10. doi: $10.2337 / \mathrm{db} 14-1870$

235. Sjoholm K, Pajunen P, Jacobson P, Karason K, Sjostrom CD, Torgerson J, et al. Incidence and remission of type 2 diabetes in relation to degree of obesity at baseline and 2 year weight change: the Swedish Obese Subjects (SOS) study. Diabetologia (2015) 58:1448-53. doi: 10.1007/s00125-015-3591-y

236. Dandanell S, Skovborg C, Praest CB, Kristensen KB, Nielsen MG, Lionett S, et al. Maintaining a clinical weight loss after intensive lifestyle intervention is the key to cardiometabolic health. Obes Res Clin Pract. (2017) 11:489-98. doi: 10.1016/j.orcp.2016.09.009

237. Knowler WC, Fowler SE, Hamman RF, Christophi CA, Hoffman HJ, Brenneman AT, et al. 10-year follow-up of diabetes incidence and weight loss in the diabetes prevention program outcomes study. Lancet (2009) 374:1677-86. doi: 10.1016/S0140-6736(09)61457-4

238. Kantae V, Nahon KJ, Straat ME, Bakker LEH, Harms AC, Van Der Stelt $\mathrm{M}$, et al. Endocannabinoid tone is higher in healthy lean South Asian than white Caucasian men. Sci Rep. (2017) 7:7558. doi: 10.1038/s41598-017-0 $7980-5$

239. Nahon KJ, Boon MR, Doornink F, Jazet IM, Rensen PCN, Abreu-Vieira G. Lower critical temperature and cold-induced thermogenesis of lean and overweight humans are inversely related to body mass and basal metabolic rate. J Therm Biol. (2017) 69:238-48. doi: 10.1016/j.jtherbio.2017. 08.006

240. Dewal RS, Stanford KI. Effects of exercise on brown and beige adipocytes. Biochim Biophys Acta (2018). doi: 10.1016/j.bbalip.2018.04.013

241. Rodrigues K, Pereira RM, De Campos TDP, De Moura RF, Da Silva ASR, Cintra DE, et al. The role of physical exercise to improve the browning of white adipose tissue via POMC neurons. Front Cell Neurosci. (2018) 12:88. doi: $10.3389 /$ fncel.2018.00088

242. Townsend LK, Wright DC. Looking on the "brite" side exerciseinduced browning of white adipose tissue. Pflugers Arch. (2018). doi: 10.1007/s00424-018-2177-1. [Epub ahead of print].

243. Bordicchia M, Liu D, Amri EZ, Ailhaud G, Dessi-Fulgheri P, Zhang C, et al. Cardiac natriuretic peptides act via p38 MAPK to induce the brown fat thermogenic program in mouse and human adipocytes. J Clin Invest. (2012) 122:1022-36. doi: 10.1172/JCI59701

244. Rao RR, Long JZ, White JP, Svensson KJ, Lou J, Lokurkar I, et al. Meteorin-like is a hormone that regulates immune-adipose interactions to increase beige fat thermogenesis. Cell (2014) 157:1279-91. doi: 10.1016/j.cell.2014.03.065
245. Hanssen MJ, Broeders E, Samms RJ, Vosselman MJ, Van Der Lans AA, Cheng $\mathrm{CC}$, et al. Serum FGF21 levels are associated with brown adipose tissue activity in humans. Sci Rep. (2015) 5:10275. doi: 10.1038/srep10275

246. Stanford KI, Middelbeek RJ, Townsend KL, An D, Nygaard EB, Hitchcox $\mathrm{KM}$, et al. Brown adipose tissue regulates glucose homeostasis and insulin sensitivity. J Clin Invest. (2013) 123:215-23. doi: 10.1172/JCI62308

247. Stanford KI, Lynes MD, Takahashi H, Baer LA, Arts PJ, May FJ, et al. 12,13-diHOME: An Exercise-Induced Lipokine that Increases Skeletal Muscle Fatty Acid Uptake. Cell Metab (2018) 27:1111-20.e1113. doi: 10.1016/j.cmet.2018.03.020

248. Arnold J, Leblanc J, Cote J, Lalonde J, Richard D. Exercise suppression of thermoregulatory thermogenesis in warm- and cold-acclimated rats. Can J Physiol Pharmacol. (1986) 64:922-6. doi: 10.1139/y86-158

249. Arnold J, Richard D. Exercise during intermittent cold exposure prevents acclimation to cold rats. J Physiol. (1987) 390:45-54. doi: 10.1113/jphysiol.1987.sp016685

250. Admiraal WM, Verberne HJ, Karamat FA, Soeters MR, Hoekstra JB, Holleman F. Cold-induced activity of brown adipose tissue in young lean men of South-Asian and European origin. Diabetologia (2013) 56:2231-7. doi: 10.1007/s00125-013-2938-5

251. Redman LM, De Jonge L, Fang X, Gamlin B, Recker D, Greenway FL, et al. Lack of an effect of a novel beta3-adrenoceptor agonist, TAK677, on energy metabolism in obese individuals: a double-blind, placebocontrolled randomized study. J Clin Endocrinol Metab. (2007) 92:527-31. doi: 10.1210/jc.2006-1740

252. Arch JR. Challenges in beta(3)-adrenoceptor agonist drug development. Ther Adv Endocrinol Metab. (2011) 2:59-64. doi: 10.1177/2042018811398517

253. Snitker S, Fujishima Y, Shen H, Ott S, Pi-Sunyer X, Furuhata Y, et al. Effects of novel capsinoid treatment on fatness and energy metabolism in humans: possible pharmacogenetic implications. Am J Clin Nutr. (2009) 89:45-50. doi: $10.3945 /$ ajcn.2008.26561

254. Chen IJ, Liu CY, Chiu JP, Hsu CH. Therapeutic effect of high-dose green tea extract on weight reduction: a randomized, double-blind, placebo-controlled clinical trial. Clin Nutr. (2016) 35:592-9. doi: 10.1016/j.clnu.2015.05.003

255. Dostal AM, Arikawa A, Espejo L, Kurzer MS. Long-term supplementation of green tea extract does not modify adiposity or bone mineral density in a randomized trial of overweight and obese postmenopausal women. J Nutr. (2016) 146:256-64. doi: 10.3945/jn.115.219238

256. Dostal AM, Samavat H, Espejo L, Arikawa AY, Stendell-Hollis NR, Kurzer MS. Green tea extract and catechol-o-methyltransferase genotype modify fasting serum insulin and plasma adiponectin concentrations in a randomized controlled trial of overweight and obese postmenopausal women. J Nutr. (2016) 146:38-45. doi: 10.3945/jn.115.222414

Conflict of Interest Statement: The GSK Chair in Diabetes of the Université de Sherbrooke held by AC has been created in part through a donation of $\$ 1$ million by GSK to the Université de Sherbrooke. AC has been recently funded by Janssen Canada to perform an investigator-initiated trial on the effect of treatment with canagliflozin on cardiac energy metabolism and function. AC has no other disclosures related to the content of this manuscript. AC holds research funding from the Canadian Institutes of Health Research, Canadian Diabetes Association, Fonds de recherche Québec-Santé, GSK, Janssen, Merck, Pfizer, AstraZeneca, Aventis, NovoNordisk, Eli Lilly, UniQure, Caprion Biosciences. AC has participated in advisory boards for the companies UniQure, Merck, Janssen and AstraZeneca and made one conference sponsored by AstraZeneca. The research and work at the basis of the present manuscript were not supported by any of these sources, aside from the GSK Chair in Diabetes of the Université de Sherbrooke.

The remaining authors declare that the research was conducted in the absence of any commercial or financial relationships that could be construed as a potential conflict of interest.

Copyright $\odot 2018$ Carpentier, Blondin, Virtanen, Richard, Haman and Turcotte. This is an open-access article distributed under the terms of the Creative Commons Attribution License (CC BY). The use, distribution or reproduction in other forums is permitted, provided the original author(s) and the copyright owner(s) are credited and that the original publication in this journal is cited, in accordance with accepted academic practice. No use, distribution or reproduction is permitted which does not comply with these terms. 